\title{
Measurement and Analysis of Spatial Reactor Profiles in High Tem- perature Catalysis Research ${ }^{1}$
}

\begin{abstract}
Spatial reactor profile measurements are a novel tool in chemical reaction engineering research. In this technique species concentrations or molar flow rates, phase temperatures and spectroscopic information are measured as function of the axial coordinate in a continuous flow tubular reactor. The obtained spatial gradients can be analyzed in terms of kinetic and mechanistic information about the reaction under study. The advantage of the spatial profile technique is that transient data are obtained at steady state and that it can be applied at temperature and pressure conditions relevant for industrial application. After a detailed description of the method various application examples are discussed such as methane catalytic partial oxidation on rhodium and platinum coated foam catalysts, methane oxidative coupling in the gas phase and oxidative dehydrogenation of ethane to ethylene on a supported molybdenum oxide catalyst. It is demonstrated how information about film transport limitation and reaction pathways can be extracted. The importance of spatial reactor profiles for validation of microkinetic models is highlighted for gas phase methane oxidative coupling at elevated pressure. Finally the idea of spatially resolved Raman spectroscopy using an optical fiber sensor is demonstrated and key parameters such as spatial resolution and position accuracy are determined.
\end{abstract}

\section{Keywords}

Reactor profiles, Methane, Ethane, Platinum, Rhodium, Molybdenum oxide, Partial oxidation, Transport limitation, Oxidative coupling, Oxidative dehydrogenation, Raman spectroscopy, Kinetic modeling

\section{Introduction}

Laboratory reactor measurements are central to research in chemical reaction engineering, answering questions such as:

1. What reaction conditions must be chosen to achieve a certain reactant conversion?

2. If consecutive or parallel reactions occur, what is the maximum yield of the target product?

3. Under which conditions is the reaction influenced by pore and/or film transport limitations?

4. Which kinetics does the reaction follow? What are the kinetic parameters?

5. What is the reaction mechanism?

Among the various reactor types used in the lab, continuous flow tubular reactors are particularly flexible. They can be designed and operated to study homogeneous gas phase reactions, homogeneous liquid phase reactions, heterogeneously catalyzed reactions of gases and liquids or even three-phase reactions in a trickle bed.

Fig. 1 shows a schematic of conventional laboratory measurements in a continuous tubular flow reactor.Precisely measured reactant streams are well mixed and fed to the reactor $\left(F_{i}^{\text {in }}, C_{i}^{\text {in }}, \dot{V}^{\text {in }}=\sum \dot{V}_{i}^{\text {in }}\right)$

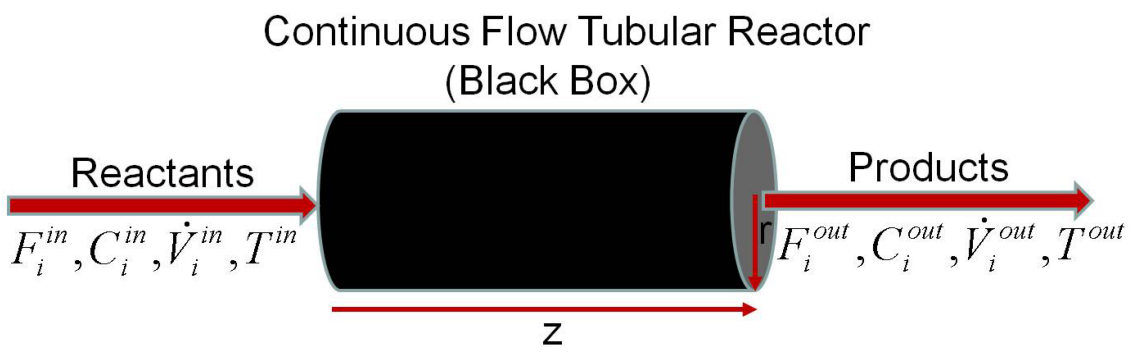

Figure 1: Conventional 'in-out' measurements in a continuous flow tubular reactor.

in which all chemical transformations occur followed by product analysis of the effluent stream $\left(F_{i}^{\text {out }}, C_{i}^{\text {out }}\right.$,

${ }^{1}$ Adapted from O. Korup, S. Mavlyankariev, M. Geske, C. F. Goldsmith, R. Horn Chem. Eng. Process. 50 (10) (2011) 998-1009. 
$\left.\dot{V}^{\text {out }}=\sum \dot{V}_{i}^{\text {out }}\right)$ using one or several analytical methods. Typically isothermicity is assumed $(T \neq f(z)$, $\left.T_{i n}=T_{\text {out }}\right)$. Integral quantities such as species consumption and production rates $\tilde{R}_{i}$, reaction rates $\tilde{r}_{j}$, reactant conversions $\tilde{X}_{i}$, product selectivities $\tilde{S}_{i}$ and yields $\tilde{Y}_{i}$ can then be calculated from the difference between inlet and outlet values as shown exemplarily for a heterogeneous catalytic reaction in Eqs. 1 . 5 ( $A_{\text {cat }}=$ catalyst surface area).

$$
\begin{aligned}
\tilde{R}_{i} & =\frac{\dot{V}^{\text {out }} C_{i}^{\text {out }}-\dot{V}^{\text {in }} C_{i}^{\text {in }}}{A_{\text {cat }}}=\frac{F_{i}^{\text {out }}-F_{i}^{\text {in }}}{A_{\text {cat }}} \\
\tilde{R}_{i} & =\sum_{j} \nu_{i j} \tilde{r}_{j} \\
\tilde{X}_{i} & =\frac{F_{i}^{\text {in }}-F_{i}^{\text {out }}}{F_{i}^{\text {in }}} \\
\tilde{S}_{k, i} & =\frac{F_{k}^{\text {in }}-F_{k}^{\text {out }}}{F_{i}^{\text {in }}-F_{i}^{\text {out }}} \frac{\nu_{i}}{\nu_{k}} \\
\tilde{Y}_{k, i} & =\tilde{X}_{i} \cdot \tilde{S}_{k, i}
\end{aligned}
$$

However, the reactor itself is treated as black box in this conventional approach. No information can be extracted at steady state from the 'in-out' quantities calculated by Eqs. 1 .5 in terms of how reactants are transformed into products, whether parallel or consecutive reaction channels exist, which reaction intermediates occur, what the state of the catalyst is along the varying chemical potential in flow direction and what temperature profile the different phases inside the reactor have. Transient experiments such as SSITKA [1] or TAP [2,3] can address some of these questions, however they are either rather costly due to use of isotopes as in SSITKA or require reactor operation (vacuum) far from industrially relevant conditions. Unrealistic reactor conditions are particularly critical as catalysts are known to be dynamic systems adapting to the reaction atmosphere inside the reactor with the consequence that the studied kinetics might not be representative for an industrial reactor.

In a flow reactor, transient processes are translated into spatial gradients in axial and radial direction. If radial gradients are minimized experimentally axial gradients can be measured and can provide kinetic and mechanistic information that is conveniently obtained at steady state without requiring expensive isotopes. Another advantage is that reactor profiles can be measured under virtually any temperature and pressure of relevance. With respect to Fig. 1, measurement of spatial reactor profiles implies the measurement of all reactor variables as a function of position, such as the concentrations or molar flow rates of fluid species $\left(C_{i}(z), F_{i}(z)\right)$, the temperature of the fluid be it gaseous or liquid $\left(T_{g}(z), T_{l}(z)\right)$, the catalyst (solid) temperature $\left(T_{s}(z)\right)$, and if possible spatially resolved spectroscopic information $(I(\lambda, z))$ characterizing the bulk and surface state of the catalyst.

In some laboratories, flow reactors have been built with a few discrete fluid sampling and temperature measurement points, so that species and temperature profiles inside the reactor can be obtained at those positions. However, in this approach typically fewer than 10 positions are sampled, and the gradients between the sampling points are often insufficiently resolved [4].

Species profiles with significantly higher resolution are obtained by continuous translation of one or more thin sampling capillaries along the flow direction of a reactor, thereby continuously transferring species into an analytical device. This method was developed independently by Partridge et al. at Oak Ridge National Lab USA [5, 6], Bosco and Vogel at the Paul Scherrer Institute in Switzerland [7] and Horn and Degenstein at the University of Minnesota USA in the group of Schmidt 8. Since their development all three reactor designs have been further developed with different foci and applied to various scientific problems. The spatially resolved capillary-inlet mass spectrometry system (SpaciMS) developed at Oak Ridge National Lab was designed to measure spatially resolved maps of species and temperatures in straight channel monoliths which are used for example in emission control catalysts for stationary and mobile applications 6]. Besides providing spatial resolution the SpaciMS was also optimized to provide superior temporal resolution for the study of transient processes which are regularly encountered in such catalysts during start up, shut down or load changes of the com- bustion engine. The SpaciMS design has been developed into a commercial product and is now distributed by Hiden Analytical UK. A comprehensive review of the development of the SpaciMS system and its various applications has been recently published 6].

Also the optically accessible channel reactor developed at the Paul Scherrer Institute has found further application for example for a spatially resolved kinetic study of CO methanation [9]. In a recent study by Schuurman et al. 10] a design quite similar to that developed at the Paul Scherrer Institute was used for spatially resolved DRIFTS in CO oxidation over Pt catalysts, even though the capillary sampling technique was not yet used in this work.

In the present paper the further development and application of the spatial profile technique by Horn et al. will be outlined. In contrast to the designs developed at Oak Ridge National Lab and at the Paul Scherrer 


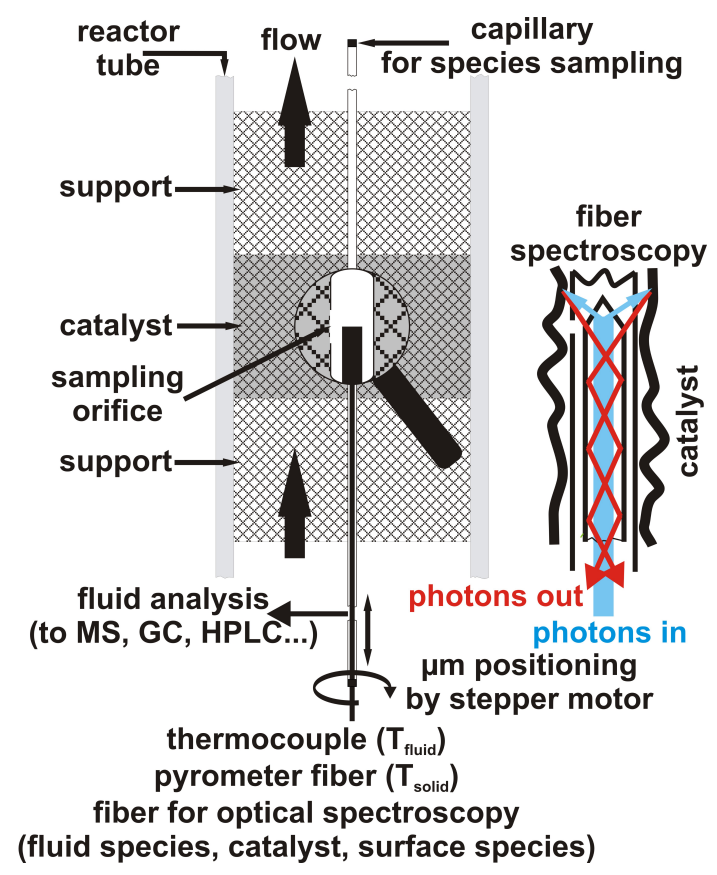

Figure 2: Principle of species, temperature and spectroscopic profile measurements in a continuous flow tubular reactor.

Institute which use an open end capillary the design by Horn et al. uses a closed capillary with a side sampling orifice such that the capillary channel remains always filled during sampling avoiding flow disturbance and bypassing induced by an open end capillary. A closed capillary design with side sampling orifice is not restricted to open channels and allows sampling along the centerline of packed beds taking advantage of the axial symmetry there. This opens up a wide application area in heterogeneous catalysis research and also offers the possibility for spatially resolved fiber spectroscopy in packed beds. A third-generation spatialprofile reactor has been developed in the High Temperature Catalysis Group at the Fritz Haber Institute of the Max Planck Society in Berlin, Germany [11]. The latest developments described in this paper concern spatial profile measurements at high reactor pressures, spatial profile measurements in packed beds, and spatially resolved laser spectroscopy using fiber probes. Current research topics - such as methane partial oxidation on Pt catalysts, gas phase methane oxidative coupling, and ethane oxidative dehydrogenation to ethylene on molybdenum catalysts - will serve as examples.

\section{Measurement of Species, Fluid and Solid Temperature Profiles, and the Principle of Spatially Resolved Fiber Spectroscopy}

The principle of spatial reactor profile measurements is shown in Fig. 2, In reference to Fig. 2, it will be outlined below how species, temperature and spectroscopic profiles are obtained. For details of the latest profile reactor operated at the Fritz Haber Institute in Berlin, the reader is referred to [11].

\subsection{Species Profiles}

For species in a flow reactor, sub-mm profiles can be obtained by continuous movement of a thin sampling capillary along the flow direction of the reactor, which continuously withdraws small samples into an analytical device such as a mass spectrometer or a gas chromatograph. Even though all published work so far is in the field of heterogeneous gas phase catalysis, application to liquid phase reactions should be straightforward using an HPLC for species analysis. In the first spatial profile reactor developed by Horn et al. 8], a thin fused silica capillary $(\mathrm{OD}=0.65 \mathrm{~mm}$ ) open at one end was used, as silica can be considered rather inert in terms of chemical surface reactivity. Even though open-end capillaries are still in use in the SpaciMS approach of Partridge et al. [6] and in the channel reactor described by Bosco and Vogel [7, Horn and Degenstein abandoned this solution in later experiments, because turbulence and backmixing that were introduced at the open end of the capillary lead to distorted profiles, as seen in [7, 8], which falsely suggested that reactant conversion and product formation began prior to contact with the catalyst. Furthermore, if irregular catalyst beds such as sphere beds or reticulated foams are investigated, an open capillary would break upon pushing back. Therefore, current measurements employ sealed capillaries with a side-sampling 


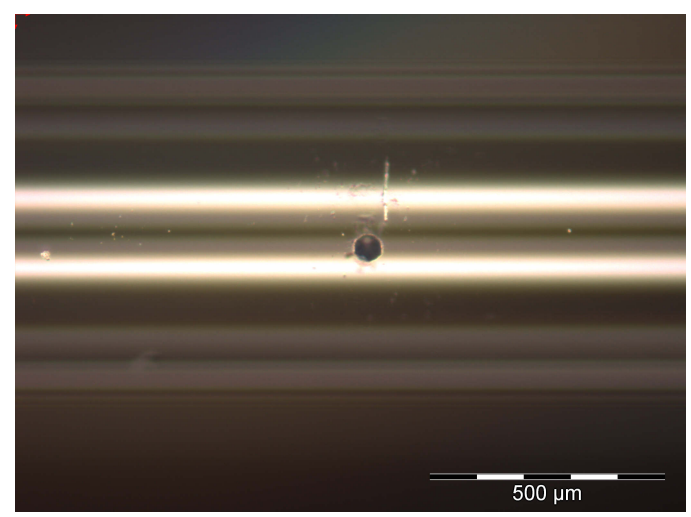

Figure 3: Laser drilled side sampling orifice in $700 \mu \mathrm{m}$ fused silica capillary.

orifice that is located at such a distance from the closed tip that the capillary channel remains filled at any sampling position (Fig. 2), thereby substantially improving the quality of the profiles 11, 12. In terms of the orifice diameter a compromise must be made between spatial resolution, sampling flow rate withdrawn from the reactor, and transfer time to the analytical device. Whereas the first orifices were scored by hand and had diameters of several hundred microns $8,12,13$, laser drilled orifices of 10-50 $\mu \mathrm{m}$ are currently in use (Fig. 3) giving a resolution of roughly 200 - 1000 sampling points per centimeter reactor length.For profile measurements the sampling capillary is moved continuously in or against flow direction using a stepper motor. Scan rates are chosen according to the gradients to be resolved. Typical values range from $1 \mu \mathrm{m} \mathrm{s}{ }^{-1}$ to $100 \mu \mathrm{m} \mathrm{s}^{-1}$. Profile measurements in packed beds require rotating the capillary back and forth as it would otherwise break upon axial movement due to shearing by the particles. Rotation is accomplished by a rotary stage fitted to the translation stage 11 .

\subsection{High Pressure Measurements}

The advantage of measuring spatial reactor profiles is that this technique can be applied to high-temperature, high-pressure conditions as frequently encountered in industry. High-pressure measurements require moving the fragile capillary with minimum force while simultaneously maintaining the reactor gas tight. In the SpaciMS design by Partridge et al. 6 flexible bellows are used to allow movement of the capillary. However, at elevated pressure the forces on these bellows become enormous, limiting this design to atmospheric or subatmospheric pressures. Bosco and Vogel used a high-temperature septum port for their capillary movement, allowing for up to 4 bar reactor pressure 7]. An alternative solution suitable for even higher reactor pressures was developed by Horn et al. 12]. Here the capillary is guided through two closely fitting liners and a grease pit in between them. Upon insertion the capillary picks up some grease, which provides both smooth move- ment through the liners and pressure sealing at the same time. With the first reactor employing this design, profile measurements up to 11 bar reactor pressure were demonstrated [14]. The current reactor operated at the Fritz Haber Institute employs a grease seal of the capillary port [11], and spatial profiles up to 40 bar pressure can be measured.

\subsection{Temperature Profiles}

Reactor temperature profiles are obtained by inserting a temperature sensor into the sampling capillary so that its tip is aligned with the sampling orifice (Fig. 2). For catalytic applications accurate measurement of the catalyst temperature is crucial. This measurement is accomplished by inserting a beveled fused silica fiber in the sampling capillary (Fig. 2, low $\mathrm{OH}$ silica for transmittance in NIR range) which collects thermal radiation from the solid catalyst and guides it to a pyrometer for temperature measurement. Because the emissivity of the solid material might change along the scan line, a two color pyrometer must be used.

If a thermocouple is inserted in the sampling capillary, its tip is in direct contact with the sampled gases but not with the solid catalyst. For this reason thermocouple profiles are strongly biased towards the gas temperature, as shown by numerical simulations of methane oxidation in $\mathrm{Rh}$ coated foam-catalysts using a 1D model that included mass and heat transfer resistances between the bulk gas phase and the solid catalyst [15]. In case of heat transfer resistance, surface and gas phase temperature profiles will deviate substantially 15,16$]$. 


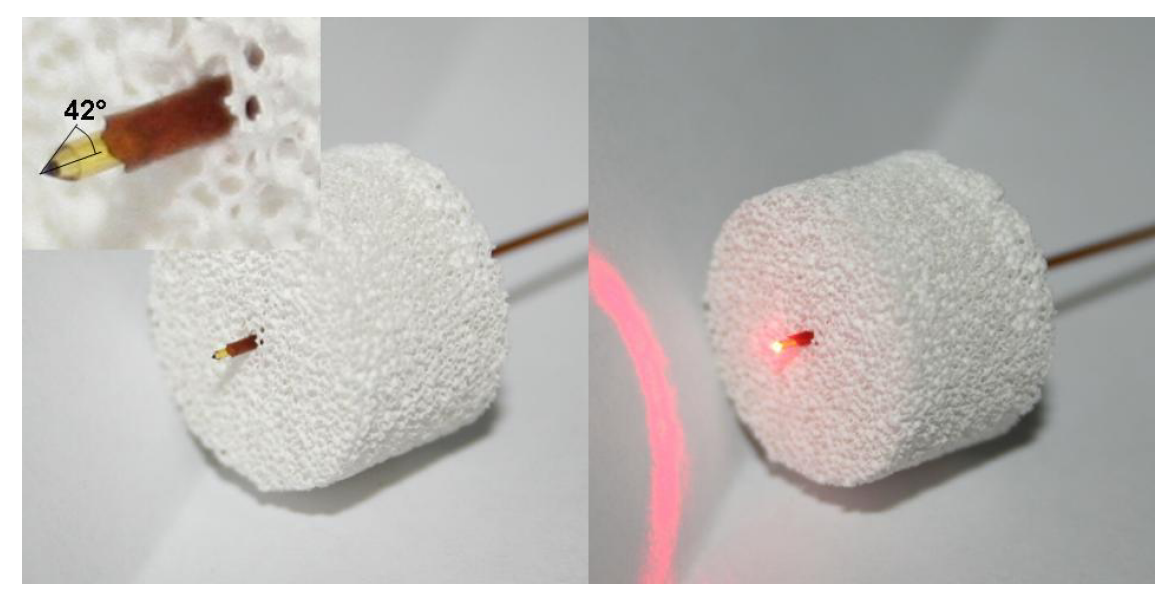

Figure 4: Illumination and angular acceptance of a properly beveled optical fiber for spatially resolved Raman spectroscopy.

\subsection{Spatially Resolved Spectroscopy}

As reviewed by Urakawa and Baiker [17], the measurement of spatially resolved spectroscopic data in catalytic reactors has recently gained a lot of attention, as catalysts are dynamic systems that continuously adapt to the local chemical potential in the reactor. Measuring spectroscopic profiles along the centerline of a catalytic flow reactor would be particularly informative, as no thermal gradients are induced by radiation losses which can be the case in many commercial or self-designed spectroscopic cells equipped with a window for optical access. Since an optical fiber can be used to guide light from the catalyst to a pyrometer for measurement of spatial temperature profiles, it is obvious that optical fibers could be used for spatially resolved spectroscopy inside the profile reactor. Even though the authors are currently focussing on Raman spectroscopy, other optical techniques such UV/vis or fluorescence spectroscopy should be compatible with the fiber approach. The most simple way of spatially resolved Raman spectroscopy using a single beveled fused silica fiber is shown in Fig. 2. Here the same fiber is used to guide the laser light to the catalyst surface, collect the scattered light, and transmit it to a spectrometer. The conical shape of the fiber tip assures illumination and acceptance of scattered light nearly perpendicular to the fiber axis (Fig. 4). A demonstration experiment will be described in Section 4 .

\section{Application Examples}

\subsection{Catalytic Partial Oxidation (CPO) of Methane on Rh and Pt Foam Cata- lysts}

The scientific motivation that originally lead to the development of the spatial profile technique in the group of Schmidt in Minneapolis was to clarify whether methane catalytic partial oxidation to syngas followed a direct or an indirect reaction scheme [8]. The pioneering work of Hickman and Schmidt showed that methane can be oxidized to syngas in excellent yields using Rh or Pt coated foam monoliths in millisecond contact time [18. Since then is has been heavily debated in the literature whether $\mathrm{CO}$ and $\mathrm{H}_{2}$ are directly formed in the presence of gas-phase oxygen (direct scheme, Eq. 6) or whether there is a combustion zone at the entrance of the foam in which $\mathrm{CH}_{4}$ is combusted to $\mathrm{CO}_{2}$ and $\mathrm{H}_{2} \mathrm{O}$ (Eq. 7) followed by steam (Eq. 8) and dry (Eq. 9 reforming, eventually producing synthesis gas (indirect scheme).

$$
\begin{array}{rlrl}
\mathrm{CH}_{4}+\frac{1}{2} \mathrm{O}_{2} & \rightarrow \mathrm{CO}+2 \mathrm{H}_{2} & \Delta_{r} \mathrm{H}^{\ominus}=-36 \mathrm{~kJ} \mathrm{~mol}^{-1} \\
\mathrm{CH}_{4}+2 \mathrm{O}_{2} \rightarrow \mathrm{CO}_{2}+2 \mathrm{H}_{2} \mathrm{O} & \Delta_{r} \mathrm{H}^{\ominus}=-803 \mathrm{~kJ} \mathrm{~mol}^{-1} \\
\mathrm{CH}_{4}+\mathrm{H}_{2} \mathrm{O} \rightarrow \mathrm{CO}+3 \mathrm{H}_{2} & \Delta_{r} \mathrm{H}^{\ominus}=+206 \mathrm{~kJ} \mathrm{~mol}^{-1} \\
\mathrm{CH}_{4}+\mathrm{CO}_{2} \rightarrow 2 \mathrm{CO}+2 \mathrm{H}_{2} & \Delta_{r} \mathrm{H}^{\ominus}=+247 \mathrm{~kJ} \mathrm{~mol}^{-1}
\end{array}
$$

\subsection{Spatial Profiles on Rh and Mechanistic Discussion}

Fig. 5 shows temperature and species profiles measured for methane CPO on a 5 wt\% Rh coated foam catalyst (experimental conditions in figure caption). From a qualitative inspection of these profiles and others measured for different conditions [8,12, it could be concluded that two reaction zones exist in a Rh 
FHS $1 w t \%$ Rh on $\alpha-\mathrm{Al}_{2} \mathrm{O}_{3}$ foam (80ppi) BHS

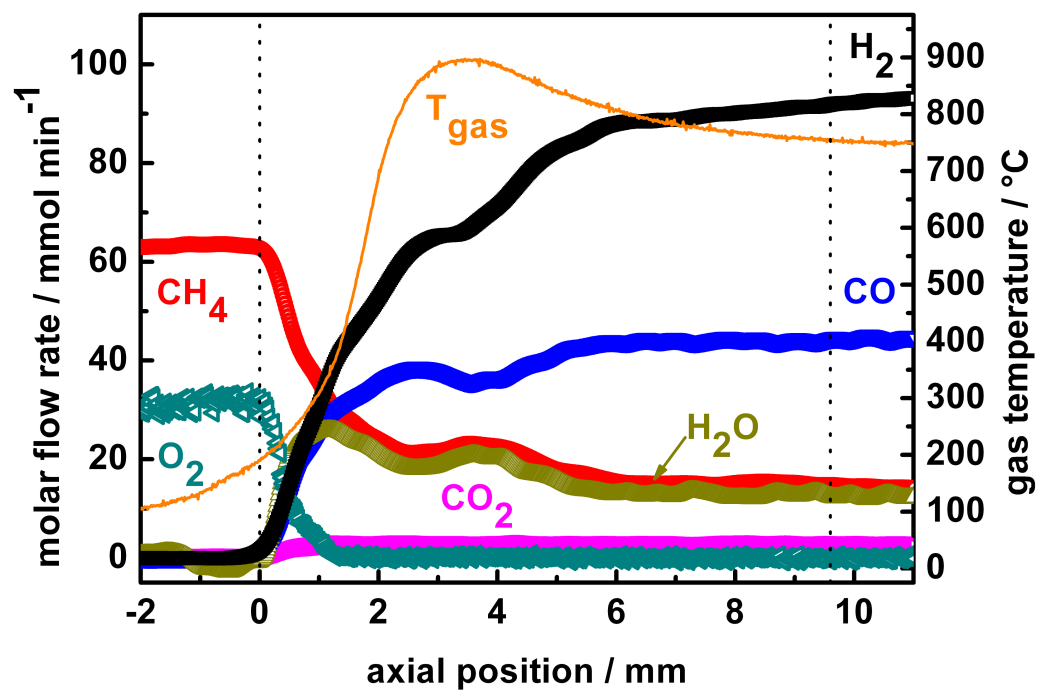

Figure 5: Species and gas temperature profiles for methane CPO on a $5 \mathrm{wt} \% \mathrm{Rh}$ coated 80 ppi foam catalyst $\left(\alpha-\mathrm{Al}_{2} \mathrm{O}_{3}\right)$. Total inlet gas stream $\dot{V}_{\mathrm{CH}_{4}}+\dot{V}_{\mathrm{O}_{2}}+\dot{V}_{\mathrm{Ar}}=4700 \mathrm{mln} \mathrm{min}^{-1}$ at $273 \mathrm{~K}$. Inlet stoichiometry $\mathrm{C} / \mathrm{O}=\dot{V}_{\mathrm{CH}_{4}} /\left(2 \cdot \dot{V}_{\mathrm{O}_{2}}\right)=1.0$ and $\dot{V}_{\mathrm{Ar}} / \dot{V}_{\mathrm{O}_{2}}=3.76\left(80 \mathrm{ppi}, L_{f}=9.6 \mathrm{~mm}, d_{f}=17 \mathrm{~mm}\right.$, porosity $\left.\varepsilon=0.7\right)$. Catalyst foam between dotted lines.

coated foam, namely a short oxidation zone at the entrance of the foam $(0 \rightarrow 1.5 \mathrm{~mm})$, followed by a longer second zone $(1.5 \rightarrow 9.6 \mathrm{~mm})$ that is dominated by steam reforming and to a minor extent watergas shift (Eq. 10). Qualitatively similar results are also found for Pt $[12$.

$$
\mathrm{CO}+\mathrm{H}_{2} \mathrm{O} \rightleftarrows \mathrm{CO}_{2}+\mathrm{H}_{2} \quad \Delta_{r} \mathrm{H}^{\ominus}=-41 \mathrm{~kJ} \mathrm{~mol}^{-1}
$$

Syngas is formed in both zones, viz. in presence of gas-phase oxidation and after complete O2 consumption by steam reforming. However, CO2 reforming (Eq.9) as suggested in the indirect scheme was never observed experimentally. Therefore, from the point of view of a formal kinetic description, methane CPO on both Rh and $\mathrm{Pt}$ can be described by Eqs. 6, 8 , and 10 .

At first glance it is surprising that $\mathrm{H}_{2}$ and $\mathrm{O}_{2}$ can co-exist in the gas phase over a $\mathrm{Rh}$ surface at temperatures around $1000{ }^{\circ} \mathrm{C}$. To rationalize this finding, the profiles in Fig. 5 and similar profiles measured for other conditions on $\mathrm{Rh}$ were modeled in several follow up publications using different elementary step reaction mechanisms 15, 16, 19. Both these model studies as well as other independent experimental studies measuring spatial profiles at varying pressure 14 revealed that methane CPO on Rh foams is nearly completely film transport limited for the stoichiometrically limiting component $\mathrm{O}_{2}$. In consequence the actual concentration of $\mathrm{O}_{2}$ in immediate vicinity of the Rh surface is essentially zero and the surface coverage of oxygen at the Rh surface negligible 15. Taking these results on Rhodium into account it has been argued by some groups 19] that the co-existence of $\mathrm{H}_{2}$ and $\mathrm{O}_{2}$ revealed by the spatial profiles 8, 12] is solely due to the vanishing $\mathrm{O}_{2}$ concentration at the Rh surface. Therefore it is an interesting question to study $\mathrm{H}_{2}$ formation by $\mathrm{CPO}$ on a catalytic system where transport limitations are much less pronounced than on Rhodium, and it will be shown in the following that this is the case on Platinum.

\subsection{Recent Work on Pt}

In comparison to Rh where irreducible mass transport limitations prevail under all experimental conditions 12], Pt is, at least from a scientific point of view, a much more interesting CPO catalyst, because early experimental studies indicate that methane CPO on Pt coated foams is much slower and kinetically controlled 12 14. This can be rationalized by simple experiments and a $1 \mathrm{D}$ mole balance on $\mathrm{O}_{2}$ which can be applied as the product of Reynolds number based on the hydraulic diameter of the ppi foam and the Schmidt number of $\mathrm{O}_{2} \mathrm{Re}_{d_{h}} \cdot \mathrm{Sc}_{\mathrm{O}_{2}} \approx 0.7$ is much bigger than $d_{h} / l_{\text {foam }} \approx 0.01$ but much smaller than $l_{\text {foam }} / d_{h} \approx 10020$.

Spatial profile measurements at constant inlet flow rate and increasing pressure on Rh remain unchanged 14 . This pressure invariance is consistent with a reaction that is complete controlled by film transport. Fig. 6 shows a similar experiment on a Pt foam catalyst, in which the pressure is raised from 1 bar to 15 bar at constant inlet gas flow. To stay outside the explosive limits, a $\mathrm{C} / \mathrm{O}$ ratio of 2 was chosen. All other conditions are given in the caption. It is clearly visible that the absolute values of the slopes of all species increase 


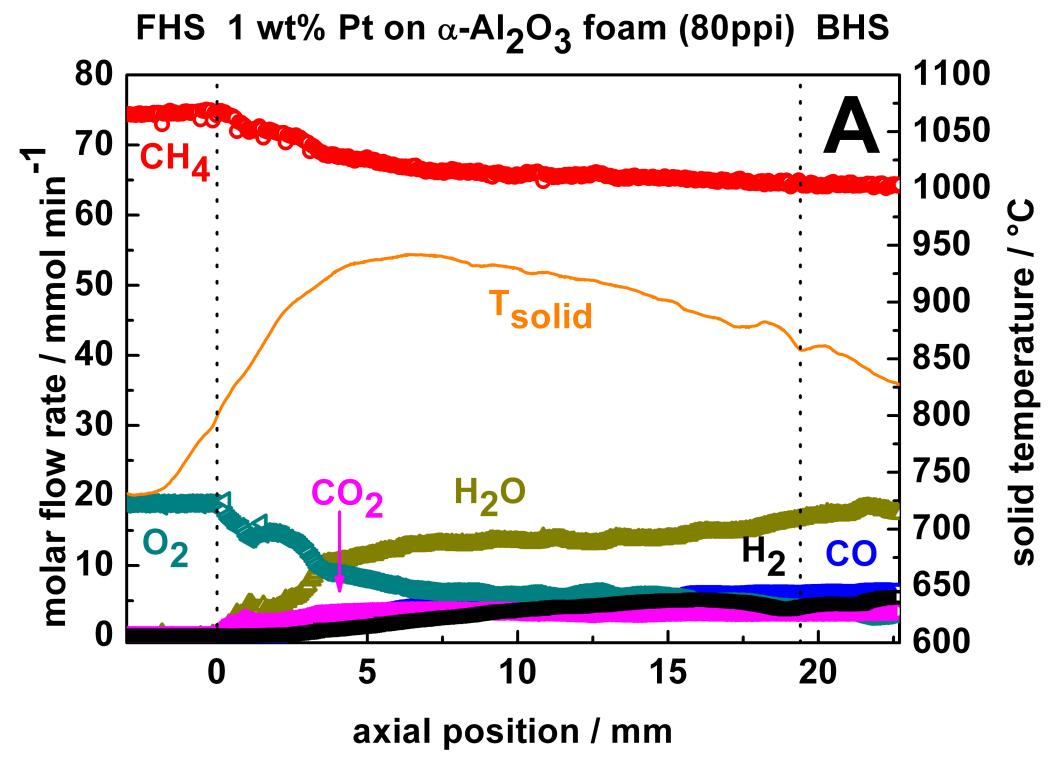

FHS $1 \mathrm{wt} \% \mathrm{Pt}$ on $\alpha-\mathrm{Al}_{2} \mathrm{O}_{3}$ foam (80ppi) BHS

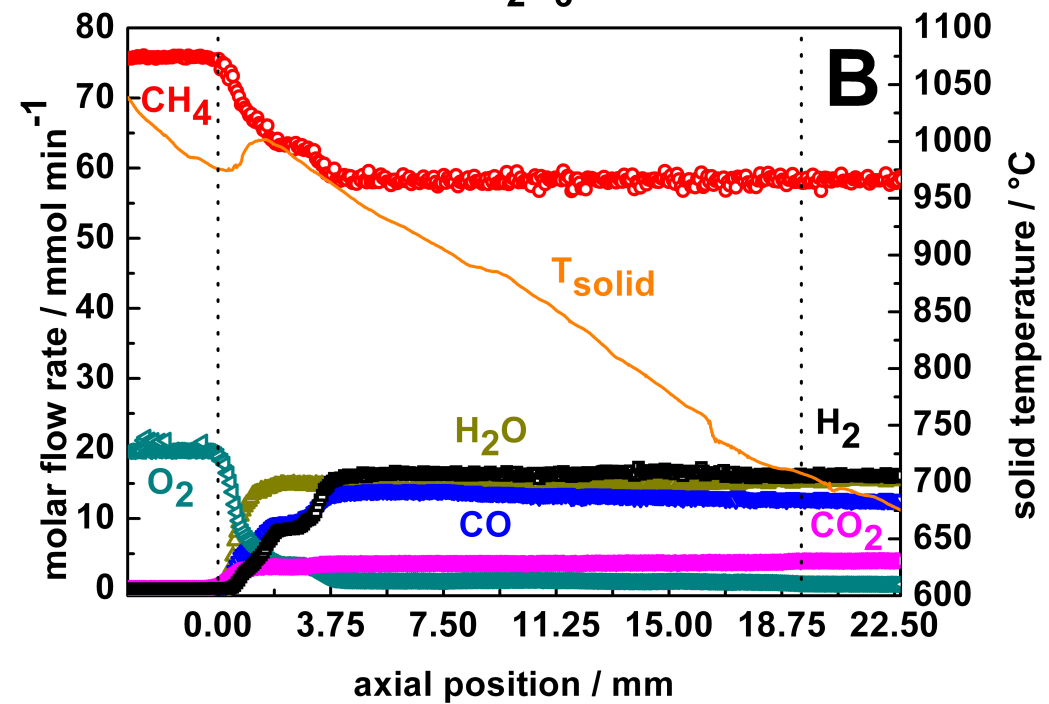

Figure 6: Spatial surface temperature profiles and species evolution through an $\alpha-\mathrm{Al}_{2} \mathrm{O}_{3}$ foam monolith coated with $1 \mathrm{wt} \% \mathrm{Pt}$ ( $80 \mathrm{ppi}, L_{f}=19.4 \mathrm{~mm}, d_{f}=15.5 \mathrm{~mm}$, porosity $\varepsilon=0.7$ ). Effect of reactor pressure. A: 1 bar, B: 15 bar. Gas feed of $\dot{V}_{\mathrm{Ar} / \mathrm{CH}_{4} / \mathrm{O}_{2}}=1718 / 1826 / 456 \mathrm{mln} \mathrm{min}^{-1}$, respectively a total gas feed of $\dot{V}_{\text {total }}=4000 \mathrm{mln} \mathrm{min}^{-1}$. 
with increasing pressure. The temperature maximum in the front heat shield must be a measurement artifact because the reactor is operated autothermally (without external heating) and no exothermic chemistry is observed in the front heat shield. This behavior is reproducibly observed in methane CPO profiles measured at elevated pressures. A potential explanation, which however still lacks experimental verification, is that methane, which has a strong absorption band at $6096.4 \mathrm{~cm}^{-1}$, absorbs selectively NIR radiation detected by the two color pyrometer at the longer measurement wavelength $\lambda_{2}=1.64 \mu \mathrm{m}$ or $\tilde{\nu}_{2}=6097.6 \mathrm{~cm}^{-1}$ but not at the shorter measurement wavelength $\lambda_{1}=1.52 \mu \mathrm{m}$ or $\tilde{\nu}_{1}=6578.9 \mathrm{~cm}^{-1}$. As the temperature value is calculated from the intensity ratio $I\left(\lambda_{1}\right) / I\left(\lambda_{2}\right)$ erroneously high temperatures are measured if NIR absorption by methane becomes pronounced. This is in particular the case at high pressures and in the front heat shield where the methane density is highest due to low gas temperatures. A quantitative correction for such a gas induced absorption of thermal radiation might be possible based on the known gas composition but has not yet been established.

Both the pressure invariance of the Rh profiles as described by Bitsch-Larsen et al. in an earlier paper 14] and the shortening of the Pt profiles in Fig. 6 are easily understood in terms of a simple $1 \mathrm{D}$ mole balance (Eq. 11) on the stoichiometrically limiting component $\mathrm{O}_{2}$, in which $R_{\mathrm{O}_{2}}$ denotes the consumption rate of $\mathrm{O}_{2}$ in mol m $\mathrm{m}^{2} \mathrm{~s}^{-1}$ at the catalyst surface (negative), $a_{c}$ the specific surface area of the foam catalyst per unit volume in $\mathrm{m}^{-1}$ and $A_{c}$ the cross sectional area of the foam in $\mathrm{m}^{2}$.

$$
\frac{d F_{\mathrm{O}_{2}}}{d z}=R_{\mathrm{O}_{2}} a_{c} A_{c}
$$

If $R_{\mathrm{O}_{2}}$ is fully determined by transport limitation, then $C_{\mathrm{O}_{2}}^{\text {surface }} \approx 0$, and $R_{\mathrm{O}_{2}}$ will be given by

$$
R_{\mathrm{O}_{2}}=-k_{c} \cdot\left(C_{\mathrm{O}_{2}}^{\mathrm{bulk}}-C_{\mathrm{O}_{2}}^{\mathrm{surface}}\right) \approx-k_{c} \cdot C_{\mathrm{O}_{2}}^{\mathrm{bulk}}
$$

with $k_{c}$ being the $\mathrm{O}_{2}$ mass transfer coefficient in $\mathrm{m} \mathrm{s}^{-1}$ and $C_{\mathrm{O}_{2}}^{\text {bulk }}$ the $\mathrm{O}_{2}$ concentration in the bulk gas phase. Taking into account that $C_{\mathrm{O}_{2}}^{\text {bulk }} \propto p$ and $k_{c} \propto p^{-1}[14$ mass transport does not speed up with increasing pressure which is why the $\mathrm{Rh}$ profiles in $[14$ are pressure invariant.

If kinetics dominate, $R_{\mathrm{O}_{2}}$ in Eq. 11 will be given by Eq. 2 . Since the various reaction rates $r_{j}$ increase with increasing reactant concentrations $\left(C_{i}^{\text {bulk }} \approx C_{i}^{\text {surface }} \propto p\right), R_{\mathrm{O}_{2}}$ will increase (become more negative), and all profiles become steeper exactly as observed in Fig. 6 .

The relative impact of film transport to surface kinetics can be estimated by calculating the highest possible slope of an $\mathrm{O}_{2}$ profile that can be achieved for a certain foam catalyst and flow conditions. Even though various transport correlations have been published for mass transfer in reticulated foam catalysts, they have usually been optimized for low cell density foams and comparably high Reynolds numbers (e.g. 10-45 ppi and $7<\operatorname{Re}<1100[21]$ or $5.9-15.3$ ppi and $15<\operatorname{Re}<200[22]$ ). In the present work 80 ppi foams with small pores $\left(d_{p} \approx 500 \mu \mathrm{m}\right)$ were used leading to very low Reynolds numbers $(\mathrm{Re} \approx 1)$ based on a hydraulic diameter 23, 24 of $d_{h}=4 \cdot \epsilon / S_{v}=4 \cdot 0.73 / 160 \times 10^{4} \mu \mathrm{m}=182 \mu \mathrm{m}\left(\epsilon=\right.$ porosity, $S_{v}=$ specific surface area [23] ) and flow field parameters extracted from the spatial profiles (e.g. Figs. 5 and 6). Because there is no doubt from experiments and simulations that the $\mathrm{O}_{2}$ profile in Fig. 5 is nearly fully film transport controlled, it is safer to extract the pseudo first-order rate constant $k_{c} \cdot a_{c}$ from an exponential fit of the $\mathrm{O}_{2}$ profile in Fig. 5 than to extrapolate a transport correlation beyond its validity range. Reformulating Eqs. 11 and 12 in terms of the limiting slope of the $\mathrm{O}_{2}$ profile in presence of full film transport yields

$$
\left(\frac{d F_{\mathrm{O}_{2}}}{d z}\right)_{\text {limit }}=-k_{c} \cdot a_{c} \cdot A_{c} \cdot C_{\mathrm{O}_{2}}^{\mathrm{bulk}} \Rightarrow\left(\frac{d C_{\mathrm{O}_{2}}^{\mathrm{bulk}}}{d z}\right)_{\text {limit }}=-\frac{k_{c} \cdot a_{c}}{u} \cdot C_{\mathrm{O}_{2}}^{\mathrm{bulk}} .
$$

Integrating Eq. 13 in which $u$ is the superficial flow velocity in $\mathrm{m} \mathrm{s}^{-1}$ yields

$$
C_{\mathrm{O}_{2}}^{\mathrm{bulk}, \mathrm{z}}=C_{\mathrm{O}_{2}}^{\mathrm{bulk}, 0} \cdot \exp \left(-\frac{k_{c} \cdot a_{c}}{u} \cdot z\right) .
$$

By fitting the experimental $C_{\mathrm{O}_{2}}^{\text {bulk, z }}$ profiles (data from Fig. 5 to the exponential function derived in Eq. 14 . the pseudo first-order rate constant $k_{c} \cdot a_{c}$ can be determined, as shown in Fig. 7 and Eq. 15. The value for the superficial velocity in the oxidation zone $u$ was calculated from the data in Fig. 5 to $u \approx 1.7 \mathrm{~m} \mathrm{~s}^{-1}$.

$$
0.46 \times 10^{-3} \mathrm{~m}=\frac{1.7 \mathrm{~m} \mathrm{~s}^{-1}}{k_{c} \cdot a_{c}} \Rightarrow k_{c} \cdot a_{c} \approx 3700 \mathrm{~s}^{-1}
$$

From the $k_{c} \cdot a_{c}$ value it is now possible to calculate the limiting slope $\left(d F_{\mathrm{O}_{2}} / d z\right)_{\text {limit }}$ in an 80 ppi foam for the $\mathrm{Pt}$ experiments that would be obtained if full film transport limitation existed.

$$
\left(\frac{d F_{\mathrm{O}_{2}}}{d z}\right)_{\text {limit }}=-k_{c} \cdot a_{c} \cdot A_{c} \cdot \bar{x}_{\mathrm{O}_{2}} \cdot C_{\text {total }}
$$




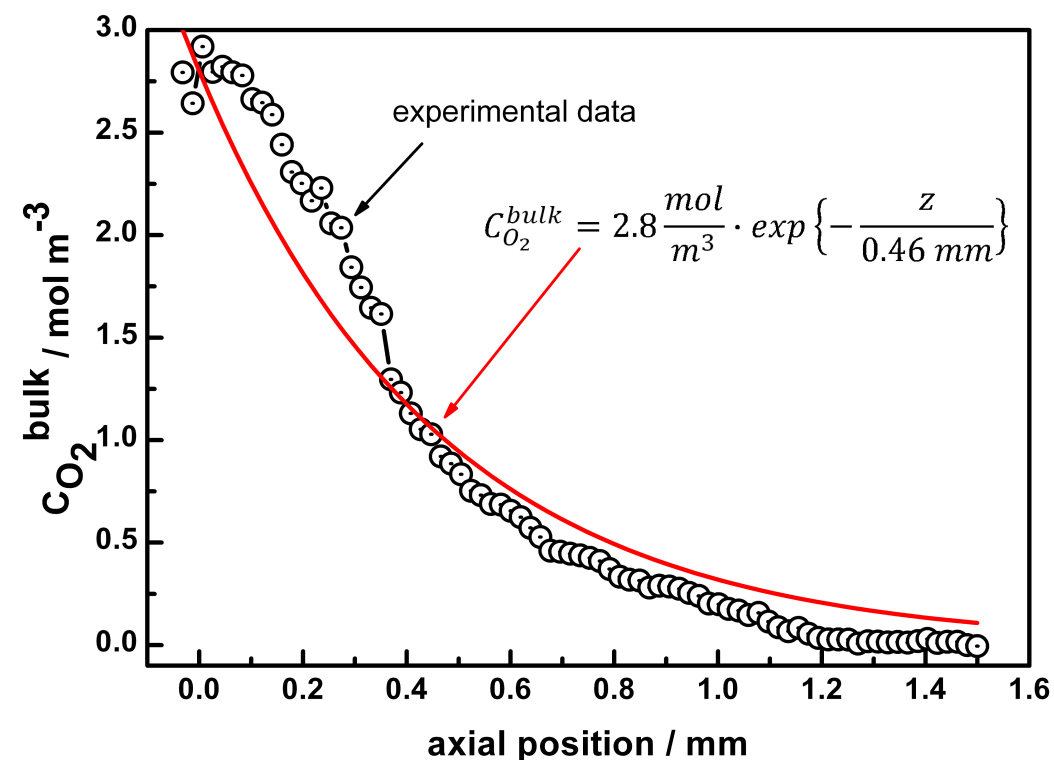

Figure 7: Determination of $k_{c} \cdot a_{c}$ by fitting Eq. 14 to the experimental data in Fig. 5 .

To compare to other experiments on 80 ppi foams, the dependence of $k_{c}$ on the inlet volumetric flow rate and on pressure has to be accounted for. This can be done by means of Eq. $17,14,22$. The mean $\mathrm{O}_{2}$ mole fraction $\bar{x}_{\mathrm{O}_{2}}$ is taken as average value over the region from which the slope is determined. The temperature dependence of $k_{c}$ is weak $\left(T^{1.3}\left[\begin{array}{l}14 \\ \text { ) }\end{array}\right)\right.$ and can be neglected as their relative variation is small (cp. Tab. 2).

$$
k_{c}\left(\dot{V}_{2}, p_{2}\right)=k_{c}\left(\dot{V}_{1}, p_{1}\right) \cdot\left(\frac{\dot{V}_{2}}{\dot{V}_{1}}\right)^{0.43}\left(\frac{p_{1}}{p_{2}}\right)^{0.93}
$$

If Eq. 16 is applied to the Rh foam profiles shown in Fig. 5 and the Pt foam profiles shown in Figs. 64A, B, and 8 A, B (experimental conditions in the figure captions) the values in Tab. 1 are obtained.

It can be clearly seen in the first row of Tab. 1 that within experimental error methane CPO on Rh coated foams is nearly fully mass transport limited. The deviation results from the imperfect fit in Fig. 7 because the data reflect to some extent the pore structure of the foam. The experimentally observed slope of the $\mathrm{O}_{2}$ profile (Fig. 6) of $-53 \mathrm{mmol} \mathrm{mm} \mathrm{min}^{-1}$ comes close to the calculated limiting value of $-83 \mathrm{mmol} \mathrm{mm} \mathrm{mm}^{-1} \mathrm{~min}^{-1}$. The situation for $\mathrm{Pt}$ is quite different. Here the ratios between the calculated limiting slopes and the experimentally observed slopes of the $\mathrm{O}_{2}$ profiles vary between 26, indicating basically no impact of film

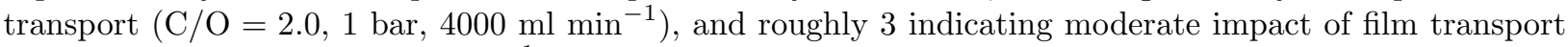
$\left(\mathrm{C} / \mathrm{O}=2.0,15 \mathrm{bar}, 4000 \mathrm{ml} \mathrm{min}^{-1}\right)$. Pt foam catalysts operate therefore in a regime largely determined by surface kinetics, which implies that the $\mathrm{O}_{2}$ concentration at the Pt surface is not much lower than in the bulk gas phase. The influence of this surface oxygen on the hydrogen selectivity is summarized in Tab. 2 Firstly, a comparison of the $\mathrm{H}_{2}$ selectivities measured on $\mathrm{Rh}$ and on $\mathrm{Pt}$ at the same reactant stoichiometry $\mathrm{C} / \mathrm{O}=1.0$ shows clearly that a pronounced film transport limitation as present on $\mathrm{Rh}$ has indeed a strong positive effect (50\% vs. $28 \%$ and $30 \%$ ) but it also makes clear that even in full kinetic control as on Pt, $\mathrm{H}_{2}$ can be formed in significant selectivities. Therefore, attributing the co-existence of $\mathrm{H}_{2}$ and $\mathrm{O}_{2}$ in the oxidation zone solely to film transport limitations is not correct. Secondly it is an interesting and new result, in particular with respect to an industrial CPO process, that $S_{\mathrm{H}_{2}}$ is not negatively influenced by pressure ( $8 \%$ at 1 bar vs. $11 \%$ at 15 bar). Therefore it would be very interesting to study CPO under pressure also at more favorable $\mathrm{C} / \mathrm{O}$ ratios if a proper reactor design would prevent explosions. 

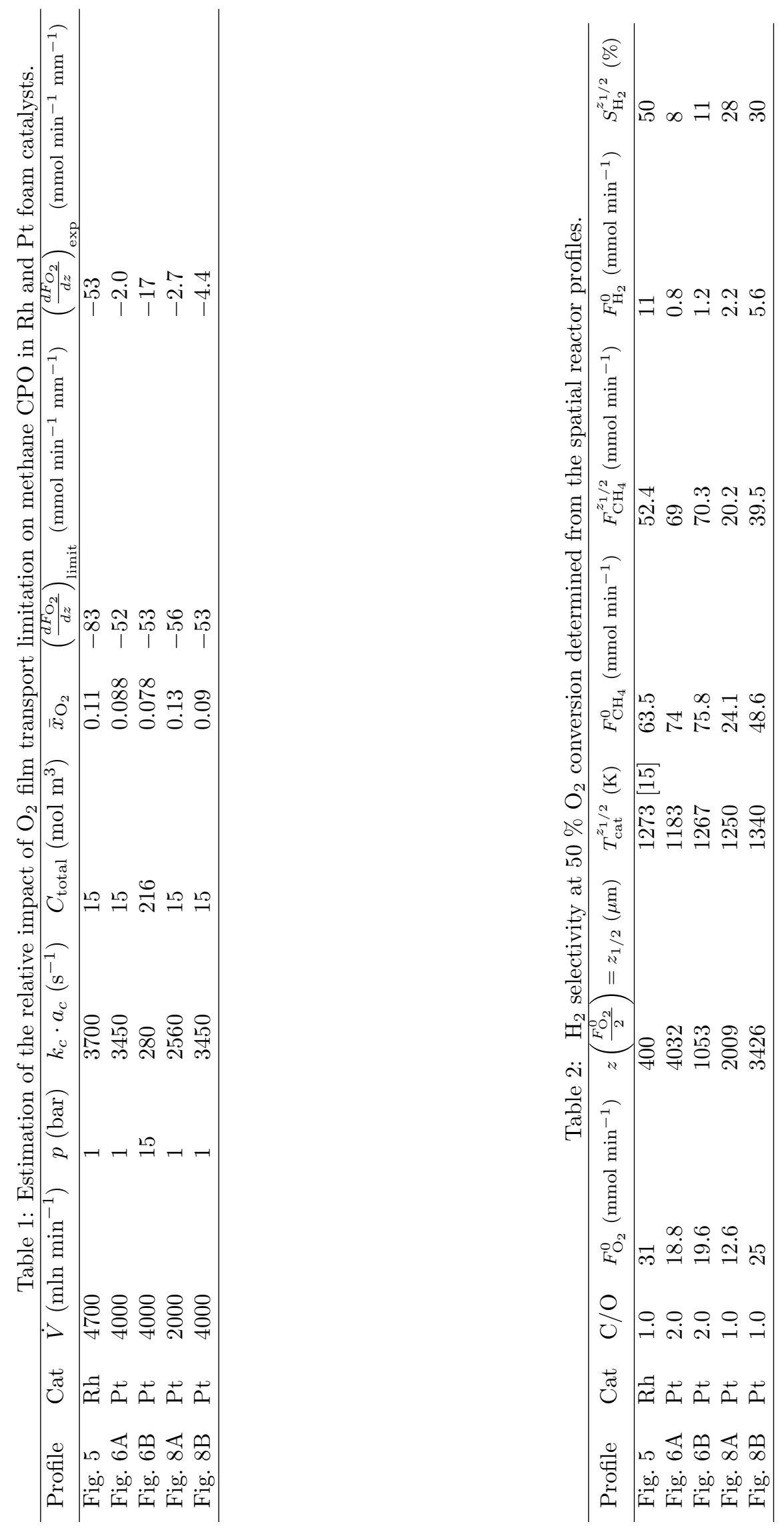


\subsection{Possible Origin of Reduced CPO Reactivity of Pt Compared to Rh}

After discussing phenomenologically the difference between $\mathrm{Rh}$ and $\mathrm{Pt}$ as $\mathrm{CPO}$ catalysts in terms of transport limitations, the question remains why the surface reactivity of $\mathrm{Pt}$ is so much lower than that of $\mathrm{Rh}$ even though both metals behave quite similarly in terms of dispersion on the support and are both excellent oxidation catalyst. This question cannot be answered in this work with certainty and will require much further research. However, an important experimental finding shall be mentioned here that might be related to the observed difference in reactivity. For Rh Dalle Nogare et al. 15 have shown numerically that the Rh surface is basically empty in the oxidation zone. This prediction still lacks experimental confirmation but it is basically what is to be expected for a catalyst surface under strict transport control.

On a Pt foil in-situ Raman experiments have revealed that the Pt surface is clean before ignition of CPO but is covered with carbon deposits immediately afterwards (cp. Fig. 9).

As will be outlined in a forthcoming article, these carbon deposits are initially rather amorphous and defect rich but become with time on stream rather graphitic and resistant to oxidation by gas-phase oxygen or steam. Similar carbon deposits have recently been reported on $\mathrm{Pt} / \mathrm{Al}_{2} \mathrm{O}_{3}$ catalysts 25 ] indicating that the observations on the $\mathrm{Pt}$ foil can be transferred to supported Pt catalysts. Therefore an obvious explanation of the reduced surface reactivity of $\mathrm{Pt}$ compared to Rh could be that these oxidation resistant carbon deposits block a majority of active sites making them inaccessible for catalysis. This argument can be substantiated by taking into account that $\mathrm{Pt}$ is an excellent hydrogenation and hence also a dehydrogenation catalyst which at high temperature obviously leads to formation of surface carbon. If this is true then current state-ofthe-art micro kinetic models have to be rewritten as none of them include such non-reactive carbon species, making it highly unlikely that they could predict spatial profiles on Pt foams correctly 26,27].

\subsection{Gas Phase Methane Oxidative Coupling}

In Section 3.1 it was illustrated for methane oxidation on Rh and Pt coated foam catalysts, how spatial profiles can be analyzed in a semi quantitative way, for example to study the influence of film transport on catalytic reactions. Another interesting aspect of spatial reactor profiles is that they have a high information density and are hence ideal datasets for comparison to microkinetic numerical simulations. For methane CPO on $\mathrm{Rh}$ foam catalysts this was already demonstrated in several publications 15, 16, 19. Because catalyst and gas temperature can be measured at any point in the reactor it is even possible to use the experimental temperature profiles as input, thereby avoiding large errors that result from solving the energy balance in cases in which heat flow from or to the reactor cannot be accurately modeled. However, it should be kept in mind that also the experimental temperature profiles of the gas phase or the solid phase measured by a thermocouple or a pyrometer fiber in the sampling capillary respectively might be biased by experimental artifacts such as thermal radiation from the oven coils or absorption of thermal radiation by gas constituents. Therefore experimental temperature profiles should only be used as input for kinetic simulations if their bias by such artifacts is small.

Oxidative coupling of methane to ethylene $(\mathrm{OCM})$ is a reaction closely related to methane partial oxidation and is currently studied by the authors, using the combined approach of spatial reactor profile measurements and microkinetic numerical simulations. This high-temperature reaction $\left(T_{r} \approx 800{ }^{\circ} \mathrm{C}\right)$ is a promising onestep reaction pathway to transform methane into ethylene, which is a valuable intermediate for the chemical industry [28. Unfortunately all research efforts have failed so far to design this reaction into a competitive technical OCM process. Interestingly there seems to be a virtual upper bound of about 25-30\% per reactor pass 28 with respect to combined $\mathrm{C} 2$ yield $\left(\mathrm{C}_{2} \mathrm{H}_{4}+\mathrm{C}_{2} \mathrm{H}_{6}\right)$, and the kinetic reason for this upper bound is unknown. Since the pioneering work of Keller and Bhasin 29] more than 2700 research articles and reviews and about 140 patents have been published on OCM, demonstrating that hundreds of chemically different materials catalyze OCM, yet there is no convincing explanation as to why all catalytic data fall roughly on or below a conversion-selectivity trajectory given by $X+S \leq 100$ [30] The most likely explanation for this indifference of OCM towards the nature of the catalytic material is that at a certain temperature methane oxidation in the gas phase dominates over catalytic oxidation steps, so that product selectivities and yields are not longer determined by the nature of the catalyst.

Spatial reactor profiles could be valuable datasets to develop a quantitative gas-phase and surface microkinetic model of OCM because they can be measured at high-temperature, high-pressure conditions, and they can provide mechanistic information on how methane and oxygen are transformed into $\mathrm{C}_{2} \mathrm{H}_{6}$ and $\mathrm{C}_{2} \mathrm{H}_{4}$ and the unwanted by-products $\mathrm{CO}$ and $\mathrm{CO}_{2}$. Validation of microkinetic models, in particular gas-phase models, requires experimental data of high information content, such as spatial profiles, since detailed kinetic mechanisms may contain hundreds of reactions, even for comparatively simple systems such as gas-phase oxidation of methane 27, 31.

To illustrate the concept Fig. 10 shows species and temperature profiles measured in the empty quartz tube of the profile reactor described in 11. This experiment was performed at 8 bar reactor pressure, a typical 


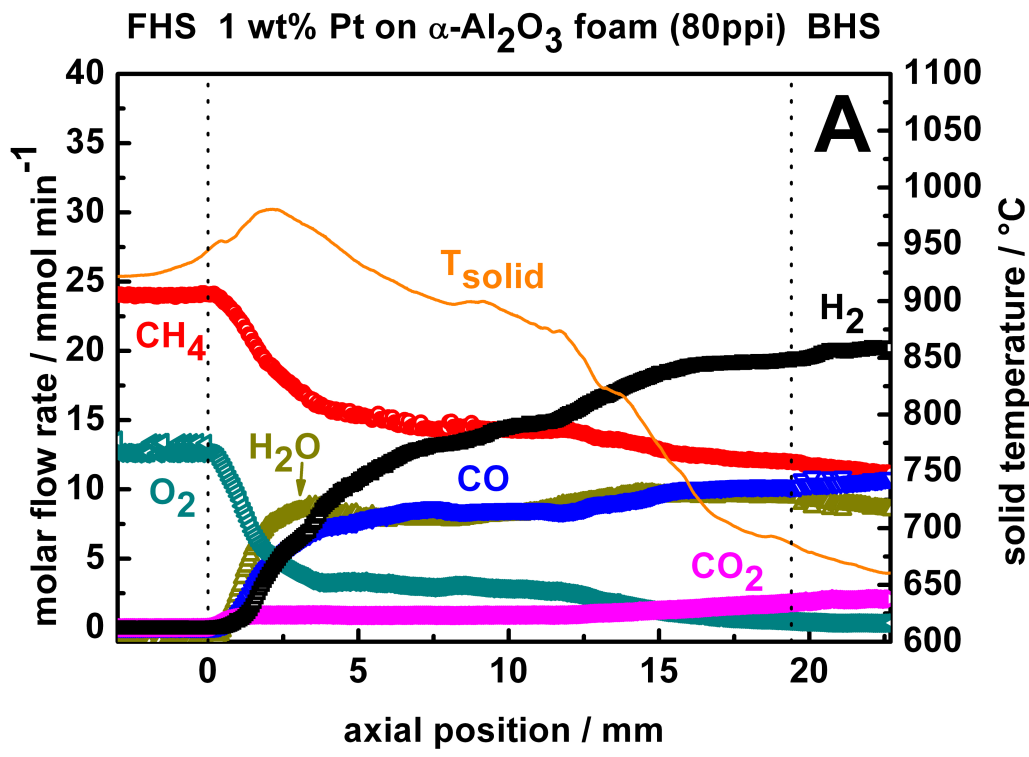

FHS $1 \mathrm{wt} \% \mathrm{Pt}$ on $\alpha-\mathrm{Al}_{2} \mathrm{O}_{3}$ foam (80ppi) BHS

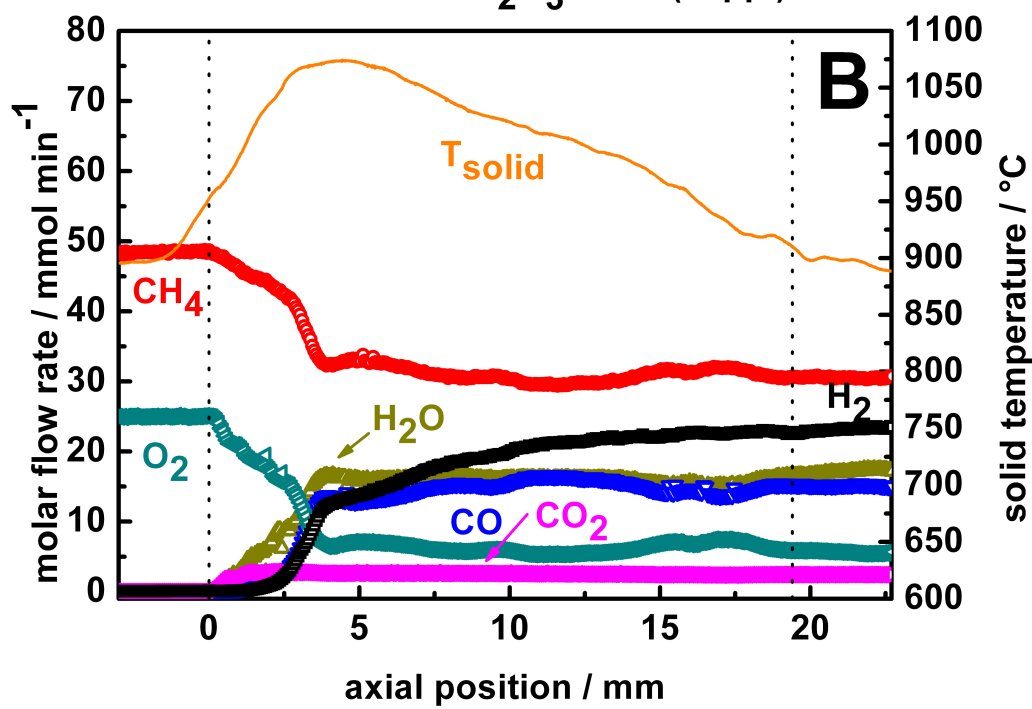

Figure 8: Spatial surface temperature profiles and species evolution through a $1 \mathrm{wt} \% \mathrm{Pt}$ coated $\alpha$ $\mathrm{Al}_{2} \mathrm{O}_{3}$ foam monolith at constant reactor pressure of $p=1$ bar. Effect of flow rate. Gas feeds: A: $\dot{V}_{\mathrm{Ar} / \mathrm{CH}_{4} / \mathrm{O}_{2}}=1112 / 592 / 296 \mathrm{mln} \mathrm{min}^{-1}$, i.e. total gas feed of $\dot{V}_{\mathrm{A}}=2000 \mathrm{mln} \mathrm{min}^{-1} ; \mathrm{B}: \dot{V}_{\mathrm{Ar} / \mathrm{CH}_{4} / \mathrm{O}_{2}}=$ $2224 / 1184 / 592 \mathrm{mln} \mathrm{min}^{-1}$, i.e. total gas feed of $\dot{V}_{\mathrm{B}}=4000 \mathrm{mln} \mathrm{min}^{-1}$. The shape of the temperature profile in (A) is probably somewhat distorted by irregularities in the pore structure along the scan line. 

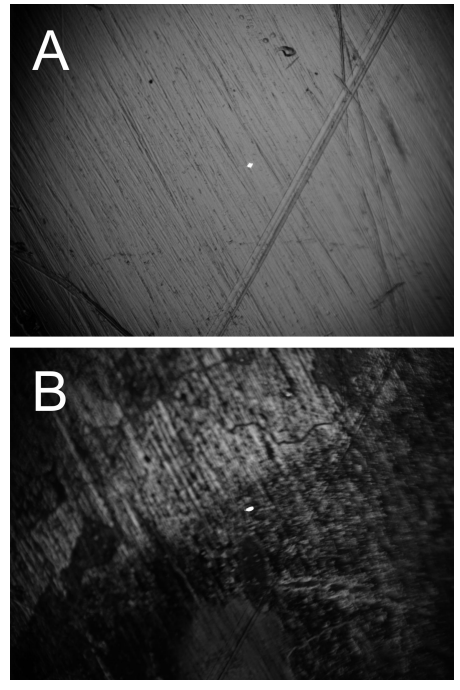

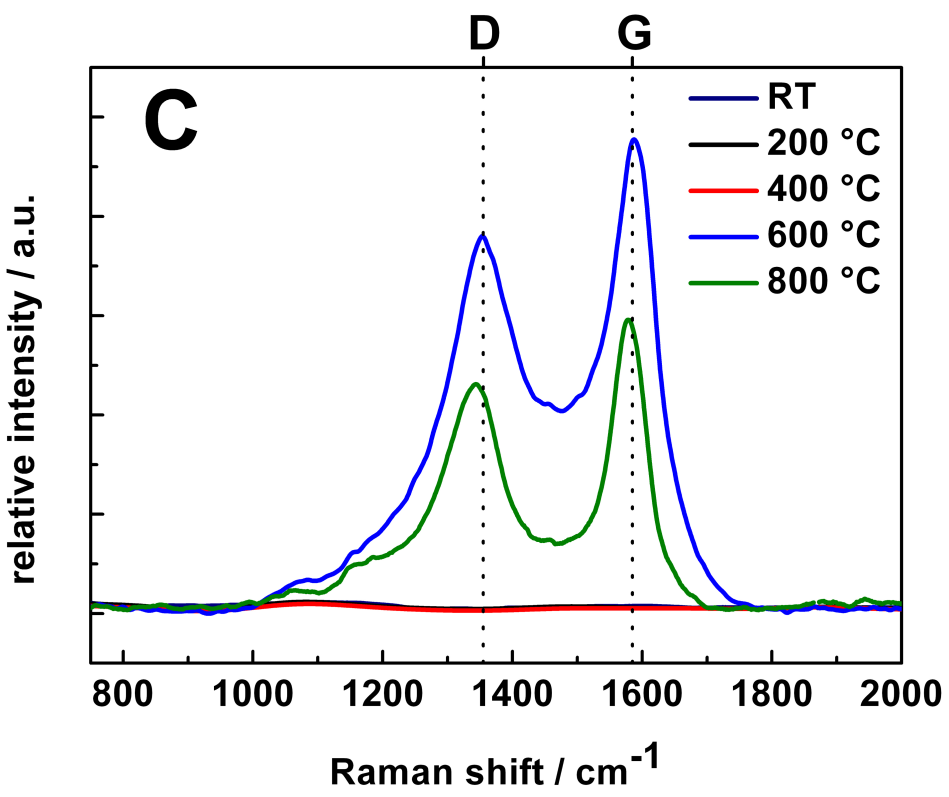

Figure 9: Microscopic picture of $\mathrm{Pt}$ foil section prior reaction light-off $(\mathrm{A})$ and after reaction light-off (B). C: In-situ Raman spectra of D and G band of carbonaceous surface deposits formed after reaction light-off.

OCM gas stoichiometry of $\mathrm{C} / \mathrm{O}=4.0$ and a total flow rate of $4000 \mathrm{mln} \mathrm{min}^{-1}\left(\dot{V}_{\mathrm{CH}_{4}}=3200 \mathrm{mln} \mathrm{min}^{-1}\right.$, $\left.\dot{V}_{\mathrm{O}_{2}}=400 \mathrm{mln} \min ^{-1}, \dot{V}_{\mathrm{Ar}}=400 \mathrm{mln} \mathrm{min}^{-1}\right)$. Blank $80 \mathrm{ppi} \alpha-\mathrm{Al}_{2} \mathrm{O}_{3}$ foam supports were used to guide the capillary and to provide a uniform flow pattern at the entrance to the free gas phase, which begins at $0 \mathrm{~mm}$. A uniform inlet flow is important for selecting proper inlet boundary conditions for the flow in the tube, which was modeled using the Boundary Layer code implemented in ChemKin Pro 32 .

As the boundary layer model requires solving the energy balance, a separate experiment was conducted to measure the oven temperature profile. For that the reactor tube was filled with a $150 \mathrm{~mm}$ long stack of graphite cylinders serving as black body for an accurate pyrometric temperature measurement. All cylinders were equipped with a central bore hole through which the pyrometer fiber could be vertically translated. After setting the oven to a certain heating power and waiting for three hours for thermal equilibration the temperature profile through the graphite cylinders was measured reflecting the oven temperature profile closely. This procedure was repeated for five different electrical heating powers. The experimental oven temperature profiles were then fitted by a third order polynomial both in position and electrical heating power. The obtained function was finally used to calculate the oven temperature profile for the heating power of $440 \mathrm{~W}$ applied in the gas phase OCM measurement shown in Fig. 10 and served as wall temperature boundary condition in the boundary layer simulation. The dashed lines in Fig. 10 represent predictions by a dedicated OCM gas-phase kinetic model, developed by Zanthoff and Baerns for gas-phase OCM at elevated pressures 33 comprising 33 species and 192 elementary reactions.

From the experimental profiles it can be seen that $\mathrm{CO}$ is the major carbon containing product in gas-phase methane oxidative coupling. $\mathrm{C}_{2} \mathrm{H}_{6}$ and $\mathrm{C}_{2} \mathrm{H}_{4}$ are formed in much smaller amounts, and it can be clearly discerned that $\mathrm{C}_{2} \mathrm{H}_{6}$ is the primary and $\mathrm{C}_{2} \mathrm{H}_{4}$ the secondary product. Interesting to note, in particular in view of the predictions by the microkinetic model, is the crossing of the $\mathrm{C}_{2} \mathrm{H}_{4}$ and $\mathrm{C}_{2} \mathrm{H}_{6}$ profile (here at $35 \mathrm{~mm}$ ) which is reproducibly observed also for other experimental conditions. The negative molar fraction of the ethylene trace between $16 \mathrm{~mm}$ and $26 \mathrm{~mm}$ is an experimental artifact from the mass spectrometric species analysis, which is due to an isobaric interference on $m / z=30$ amu by $\mathrm{C}_{2} \mathrm{H}_{6}, \mathrm{CH}_{3} \mathrm{OH}$ and $\mathrm{CH}_{2} \mathrm{O}$. As $30 \mathrm{amu}$ is used to correct the ethylene peak at $27 \mathrm{amu}$ for ethane fragmentation at this mass, negative peak areas are always obtained when the signal at $30 \mathrm{amu}$ is caused by $\mathrm{CH}_{3} \mathrm{OH}$ and $\mathrm{CH}_{2} \mathrm{O}$, which are formed in trace amounts at low temperatures. There is basically no $\mathrm{CO}_{2}$ formation by gas-phase methane oxidation in contrast to catalytic OCM where $\mathrm{CO}_{2}$ is the dominant product (not shown). It can be further seen that there is an ignition-delay zone $(0-16 \mathrm{~mm})$ at the beginning of the free gas phase where no noticeable chemistry occurs. This ignition delay is a combined effect of the increasing temperature and the build- ing up of a radical pool. Experimental reactant conversion and product formation begin at about $16 \mathrm{~mm}$ axial position and continue until the end of the free gas phase. $\mathrm{C}_{2} \mathrm{H}_{4}$ reaches maximum concentration at around $57 \mathrm{~mm}$ and is then consumed by steam reforming.

The kinetic model 33] captures the final gas composition at the reactor outlet sufficiently well, but it does not reproduce the species development inside the reactor. Sufficient reproduction of reactor exit concen- 


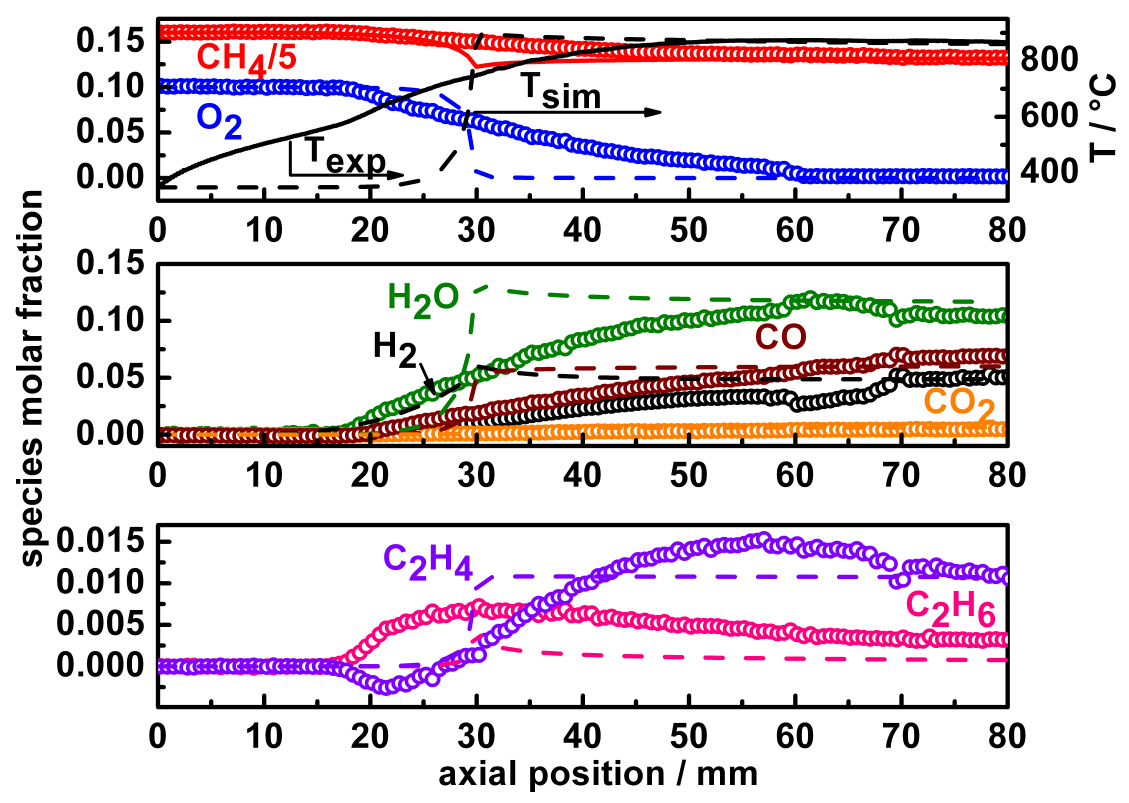

Figure 10: Experimental reactor profiles (scatter) and boundary layer numerical simulations (dashed lines) of gas phase methane oxidative coupling. Reactor pressure $p=8$ bar, reactant stoichiometrie $\mathrm{C} / \mathrm{O}=4.0$,

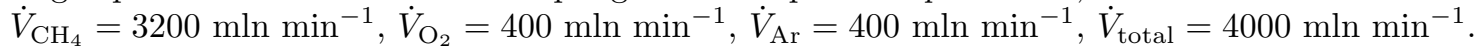

trations has been observed not only for the kinetic model used in this work 33 but also for other models tested, probably because these models have been optimized to fit OCM reactor outlet data well.

The species development in Fig. 10 as predicted by the model is basically confined to a narrow region between 20 and $30 \mathrm{~mm}$ whereas the experimental profiles develop over a much longer length between 16 and $81 \mathrm{~mm}$. Consequently the numerically predicted gradients are too steep and not in quantitative agreement with the experimental data. Also important qualitative features of the experimental profiles such as the crossing of the $\mathrm{C}_{2} \mathrm{H}_{6}$ and the $\mathrm{C}_{2} \mathrm{H}_{4}$ profiles are not reproduced by the model indicating severe deficiencies in terms of the included reaction steps and/or the kinetic parameters.

Even though the used boundary layer model is an appropriate description for the flow in the empty reactor tube one notes the dis- agreement between the simulated centerline gas temperature $T_{\text {sim }}$ and the temperature measured by the thermocouple in the sampling capillary $T_{\exp }$. Between 0 and $25 \mathrm{~mm}$ where the experimental temperature increases rapidly the centerline gas temperature in the boundary layer simulation increases only slowly. However, this could be realistic as the linear flow velocity of the gas is rather high starting from $6.8 \mathrm{~cm} \mathrm{~s}^{-1}$ at the inlet and increasing up to $13 \mathrm{~cm} \mathrm{~s}^{-1}$ at the end of the free gas phase section. Furthermore because the thermocouple is not only in contact with the sampled gases but sees also radiation from the oven coils it could be argued that the thermocouple temperature is biased to values which are too high and that the simulated temperature is more realistic. How strongly the thermocouple temperature profiles deviates from the true gas temperature profile will be investigated in the future using CFD simulations combined with appropriate heat transport by conduction, convection and radiation.

In summary it was shown for the example of methane oxidative coupling in the gas phase how spatial reactor profiles can be used to validate even substantial microkinetic reaction models comprising several dozens species and up to several hundred reactions. It could be demonstrated that even in cases where reactor outlet data are described sufficiently well by the model the species development in the reactor can still be falsely predicted. If spatial reactor data are used for validation it will be possible to optimize model parameters in such a way that the model also captures the development of the various species correctly, provided that all parameters stay within physically reasonable bounds.

\subsection{Oxidative Dehydrogenation of Ethane to Ethylene on Molybdenumoxide Catalysts}

For the final example of spatial reactor profiles in this work a transition metal oxide catalyzed reaction has been chosen, namely oxidative dehydrogenation of ethane to ethylene (ODH) on a molybdenum oxide catalyst. Transition metal oxide catalysts are interesting to study by spatial profiles, as they can change their oxidation state and can adjust to the changing chemical potential of the gas. Similar to OCM, ODH is an industrially interesting production route of ethylene and has therefore received considerable scientific attention 34,35 . 

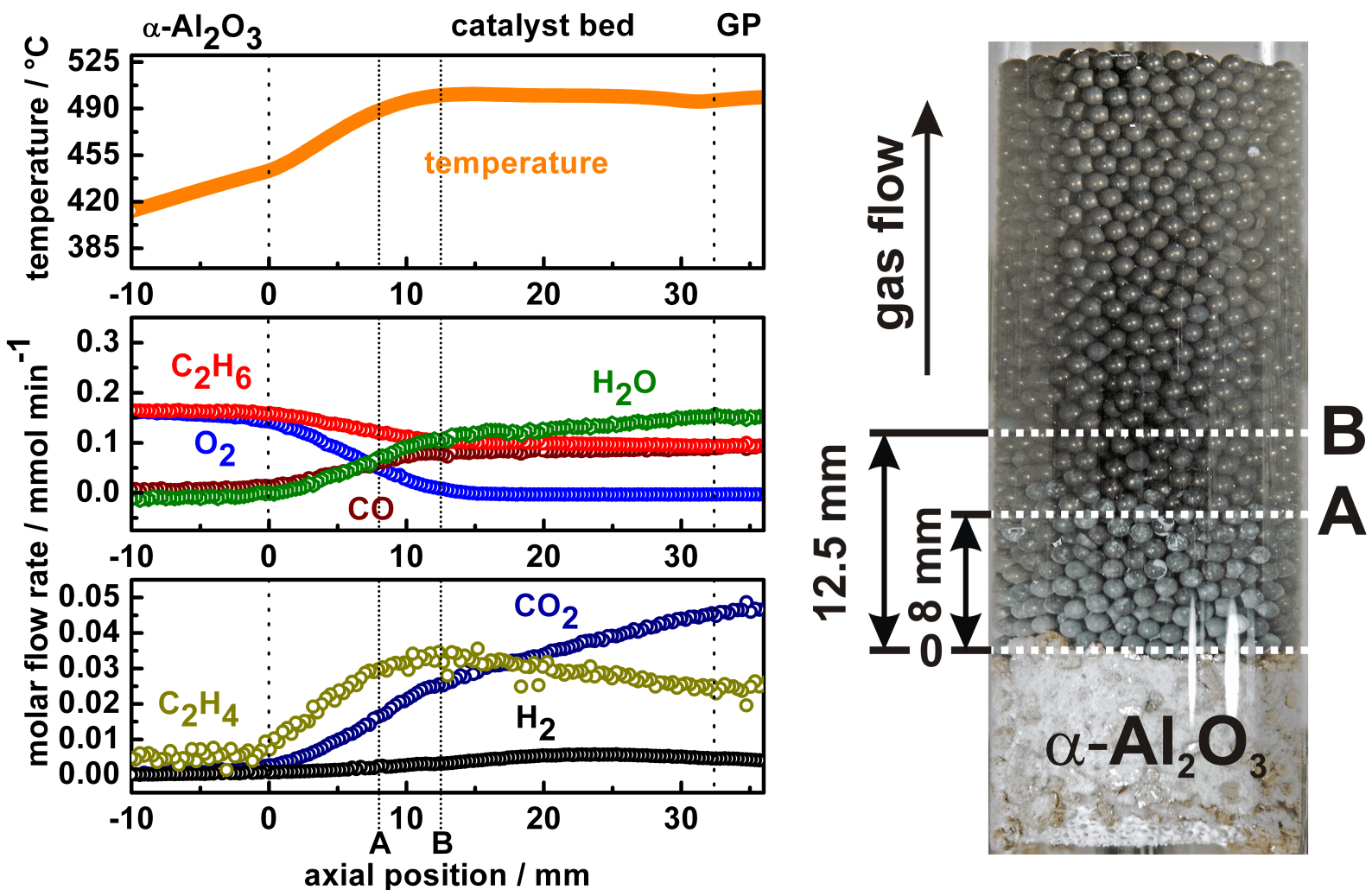

Figure 11: Left: Species and catalyst temperature profiles for ethane $\mathrm{ODH}$ on $\mathrm{MoO}_{x}$ coated $\alpha-\mathrm{Al}_{2} \mathrm{O}_{3}$

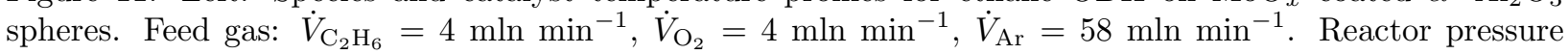
$p=1$ bar. Right: Photograph of the sphere bed after $3 \mathrm{~h}$ time on stream.

Various chemically different catalysts are active for $\mathrm{ODH}$, among them noble metals such as Pt, oxides of group IA and IIA metals e.g. $\mathrm{Li} / \mathrm{MgO}$, and transition metal oxides e.g. $\mathrm{VO}_{x}, \mathrm{MoO}_{x}$. We applied the spatial profile technique to ethane $\mathrm{ODH}$ on $\mathrm{MoO}_{x}$ supported on $\gamma-\mathrm{Al}_{2} \mathrm{O}_{3}$ spheres to resolve how gas composition and temperature influence the redox state of the catalyst, which was analyzed ex-situ after quenching. For this purpose we adjusted the feed rate such that complete $\mathrm{O}_{2}$ conversion was reached in the bed in contrast to regular partial oxidation catalysis where full $\mathrm{O}_{2}$ conversion has to be avoided.

A $3 \mathrm{~cm}$ high bed of catalyst spheres $\left(d_{s}=1 \mathrm{~mm}\right)$ was placed inside the profile reactor held in place by an 80 ppi $\alpha-\mathrm{Al}_{2} \mathrm{O}_{3}$ support foam. The catalyst spheres were prepared by incipient wetness impregnation of $\gamma-\mathrm{Al}_{2} \mathrm{O}_{3}$ spheres (Sasol, $157 \mathrm{~m}^{2} \mathrm{~g}^{-1}$ ) using an aqueous solution of $\left(\mathrm{NH}_{4}\right)_{6} \mathrm{Mo}_{7} \mathrm{O}_{24} \cdot 4 \mathrm{H}_{2} \mathrm{O}$ such that a $30 \mathrm{wt} \%$ $\mathrm{MoO}_{3}$ loading was achieved. After drying at $120{ }^{\circ} \mathrm{C}$ the spheres were calcined at $540{ }^{\circ} \mathrm{C}$ for $6 \mathrm{~h}$.

For profile measurements a gas mixture consisting of $4 \mathrm{mln} \min ^{-1} \mathrm{C}_{2} \mathrm{H}_{6}, 4 \mathrm{mln} \mathrm{min}{ }^{-1} \mathrm{O}_{2}$ and $58 \mathrm{mln} \mathrm{min}^{-1}$ Ar was fed to the reactor. The maximum reactor temperature was adjusted to stay below $520{ }^{\circ} \mathrm{C}$ to avoid sublimation of $\mathrm{MoO}_{3}$. The species and temperature profiles as well as a photograph of the sphere bed quenched after $3 \mathrm{~h}$ time on stream are shown in Fig. 11. Oxygen is consumed after passing about $12.5 \mathrm{~mm}$ of the catalyst bed (point B). Oxidation products are $\mathrm{C}_{2} \mathrm{H}_{4}, \mathrm{CO}, \mathrm{CO}_{2}$ and $\mathrm{H}_{2} \mathrm{O} . \mathrm{H}_{2}$ formation is negligible in the entire bed. As can be seen on the photograph of the sphere bed, the $\mathrm{MoO}_{x}$ catalyst reacts sensitively to the gradually declining $\mathrm{O}_{2}$ concentration in the gas phase by changing its color from gray to dark-violet. The color transition occurs after about $8 \mathrm{~mm}$ where $70 \%$ of the initial $\mathrm{O}_{2}$ has been converted $\left(T^{8 \mathrm{~mm}}=757 \mathrm{~K}\right.$, $C^{8 \mathrm{~mm}}=0.3 \mathrm{~mol} \mathrm{~m}{ }^{-3}, p^{8 \mathrm{~mm}}=1850 \mathrm{~Pa}$ ). Ex-situ XRD analysis (not shown) revealed that the gray spheres in the oxidation zone consist mainly of $\mathrm{Al}_{2}\left(\mathrm{MoO}_{4}\right)_{3}$ and trace amounts of $\mathrm{MoO}_{2}$. The presence of $\mathrm{MoO}_{4}$ tetrahedrons both in polymeric and monomeric form was also confirmed by ex-situ Raman spectroscopy. The dark-violet spheres showed a characteristic Raman signature of phase pure $\mathrm{MoO}_{2}$ which was also confirmed by XRD. Therefore it can be concluded that the bulk phase of the catalyst consists of molybdenum in + VI oxidation state as long as the $\mathrm{O}_{2}$ gas phase pressure is higher than about $1850 \mathrm{~Pa}$ and at lower values it is produced to $+\mathrm{IV}$ as in $\mathrm{MoO}_{2}$.

From the $\mathrm{CO}_{2}$ production after full consumption of gas-phase $\mathrm{O}_{2}$ it can be seen that the reduction of the catalyst bed has not been finished in this experiment, due to the high amount of catalyst compared to the small feed rate of hydrocarbons. Very interestingly lattice oxygen seems to oxidize preferentially the target 


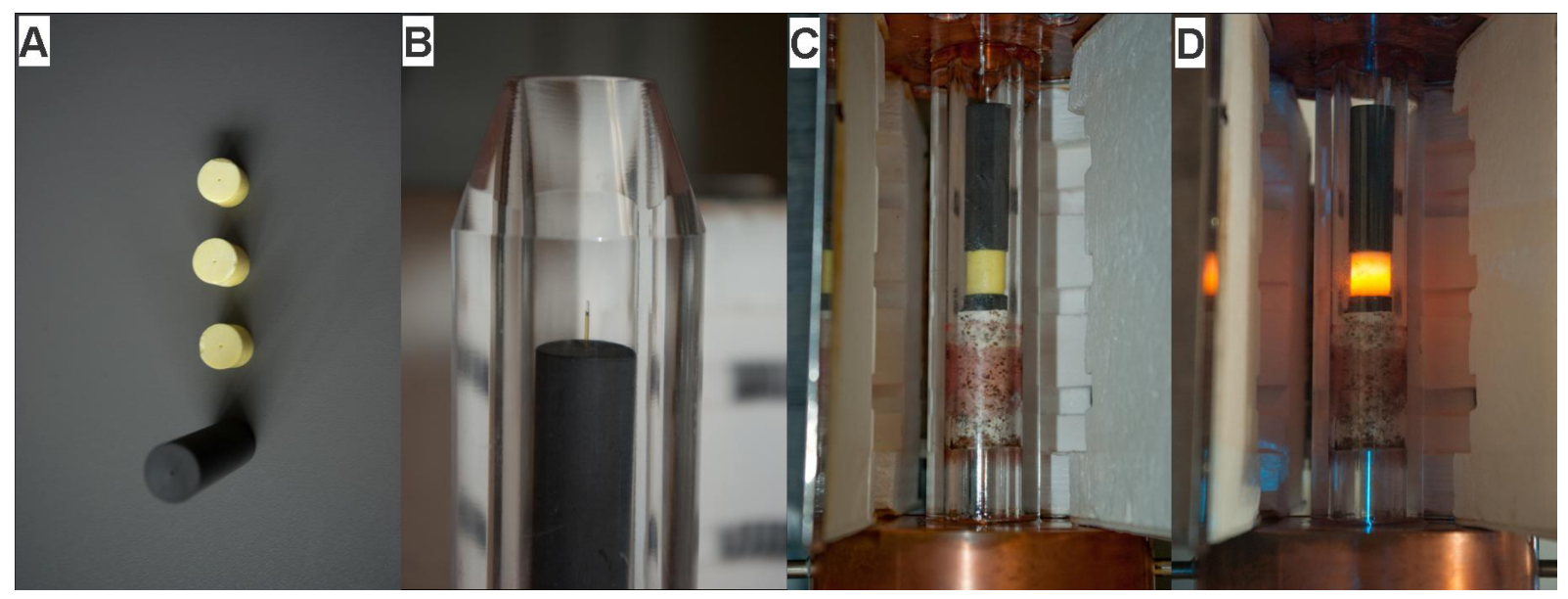

Figure 12: A: Graphite and sulfur cylinders for demonstrating the principle of spatially resolved Raman spectroscopy. B: Optical fiber sticking out of the sampling capillary which was inserted in the graphite sulfur stack. C: Assembly mounted in the profile reactor. D: Spatially resolved Raman in operation - fiber tip in the center of the sulfur cylinder.

product $\mathrm{C}_{2} \mathrm{H}_{4}$ to $\mathrm{CO}_{2}$ and $\mathrm{H}_{2} \mathrm{O}$ whereas $\mathrm{C}_{2} \mathrm{H}_{6}$ is obviously preferentially oxidized by gas phase $\mathrm{O}_{2}$ (Fig. 11 ). In summary spatial reactor profile measurements can also bring new insight in transition metal oxide catalysis as it becomes possible to correlate measured kinetic data to information about the chemical state of the catalyst. Current developments of the spatial profile technique in the authors lab aim to extent the spatial profile technique to spatially resolved optical spectroscopy as will be described in forthcoming papers. Simultaneous measurement of species, temperature and spectroscopic profiles would provide in-situ information about the catalyst without that quenching and ex-situ characterization will be necessary. With this technique at hand, spatially resolved transients, isotope labeling and other interesting in-situ experiments will become feasible. A proof of principle experiment for spatially resolved Raman spectroscopy is described in the following section. For first catalytic applications, the reader is referred to forthcoming articles.

\section{Spatially Resolved Fiber Spectroscopy}

To demonstrate the principle of spatially resolved optical spectroscopy with a fiber probe inside the species sampling capillary, Raman spectroscopy was chosen as the initial method. An $\mathrm{Ar}^{+}$laser $(300 \mathrm{~mW}, 488 \mathrm{~nm})$ was coupled into a bare fluorine doped fused silica fiber $(\mathrm{OD}=440 \mu \mathrm{m})$. The fiber tip was beveled (cone angle $42^{\circ}$, Fig. 4 left) such that the acceptance angle of the fiber was nearly perpendicular to the fiber axis (Fig. 4 right). Scattered light was collected by the same fiber and transferred into a fiber bundle consisting of 19 fluorine doped fused silica fibers $(\mathrm{OD}=110 \mu \mathrm{m})$ arranged in a circular closed package at the reactor side and on top of each other in form of a line (height $2 \mathrm{~mm}$ ) at the spectrometer side. The scattered light was analyzed by means of a triple filter Raman spectrometer (TriVista S\&I GmbH) with a CCD camera as detector operated in subtractive mode.

To study the spatial resolution of this arrangement and the influence of the surrounding sampling capillary a stack of sulfur/graphite cylinders $(\mathrm{OD}=15 \mathrm{~mm})$ was prepared so that a sharp transition from a good Raman scatterer (sulfur) to a very poor highly absorbing Raman scatterer (graphite) was created (Fig. 12 ). All cylinders had a central channel fitting the sampling capillary tightly. As shown in Fig. 13 the actual measured spectra are a linear superposition of the Raman spectrum of the fiber material (fused silica) and the Raman spectrum of the sample at the place of analysis. To remove the fused silica background blank spectra were measured with high accuracy outside of the graphite/sulfur stack and subtracted after normalization from all spectra measured inside the stack. The difference spectra are plotted as function of position in the right panel of Fig. 13 . Position accuracy and spatial resolution of the method were determined as shown in Fig. 14. One intense sulfur Raman peak at $480 \mathrm{~cm}^{-1}$ and one weak sulfur Raman peak at $446 \mathrm{~cm}^{-1}$ were $^{-14}$ integrated and plotted against position (upper panels). This was done both for the data measured when the fiber tip was outside of the sampling capillary (left panels in Fig. 14) and when the fiber tip was inside the sampling capillary (right panels in Fig. 14). As the step like functions obtained (Fig. 14 upper panels) are a convolution between a nearly perfect step function (sulfur - graphite interface) and the spread function of the optical arrangement (fiber + spectrometer), the latter can be obtained by calculating the first derivative of the spatial data around the sulfur - graphite transition (Fig. 14 lower panels). The analysis shows that the position accuracy is excellent as only a small offset of about $350-370 \mu \mathrm{m}$ exists. This small offset is due to the fact that the acceptance angle of the fiber is somewhat less than $90^{\circ}$. The spread function of 

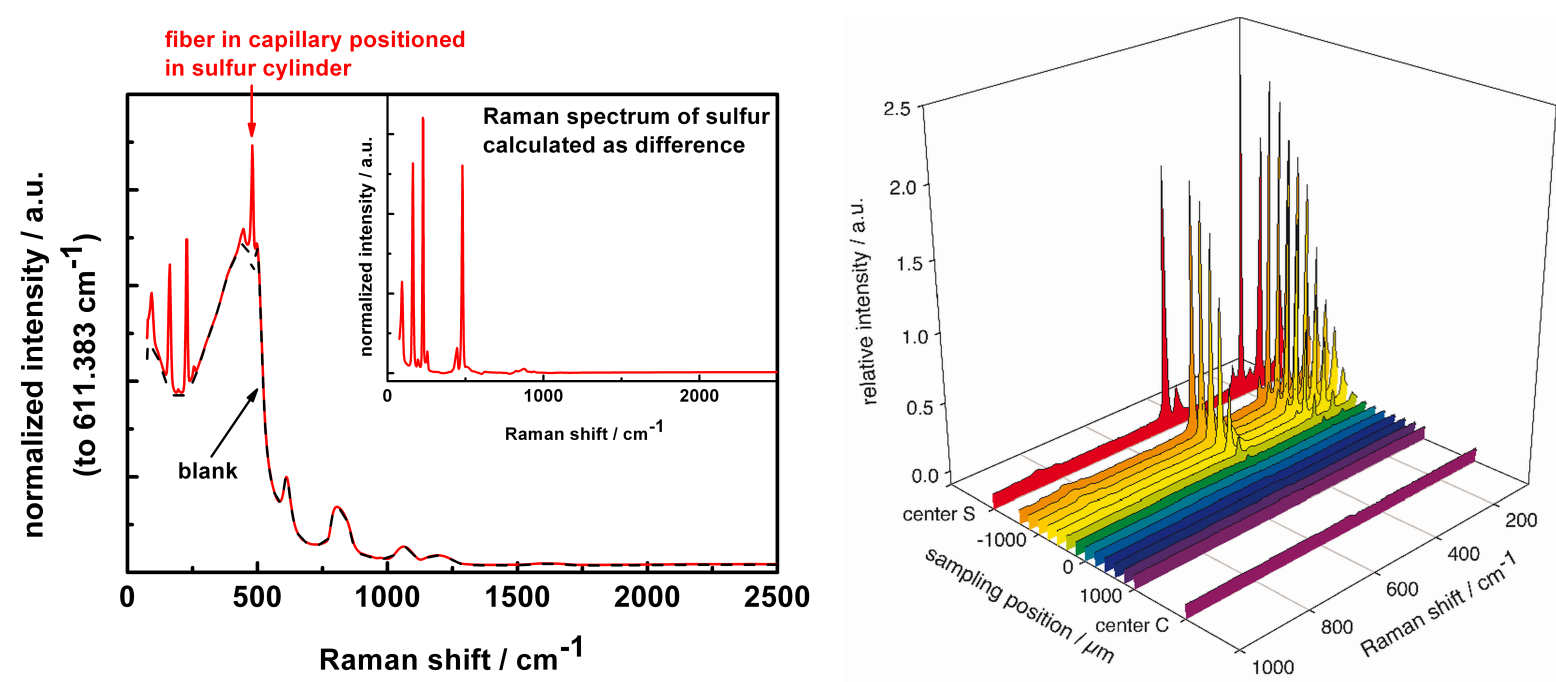

Figure 13: Left: Single Raman spectra of the fiber tip in air (blank measurement, dotted line). Raman spectrum with fiber tip positioned in the sulfur cylinder (solid line). Raman spectrum of sulfur calculated as difference (inset). Right: Background corrected Raman spectra measured around the graphite - sulfur transition.

the optical system can be well fitted by a Gaussian function (solid lines in the lower panels of Fig. 14). If the Full Width at Half Maximum (FWHM) of the Gaussian is taken as a measure for the spatial resolution of the method then a spatial resolution of $620-650 \mu \mathrm{m}$ can be achieved, which is more than sufficient for catalysis applications, since most catalytic variations occur over many millimeters if or even centimeters (Section 3.1-3.6). 

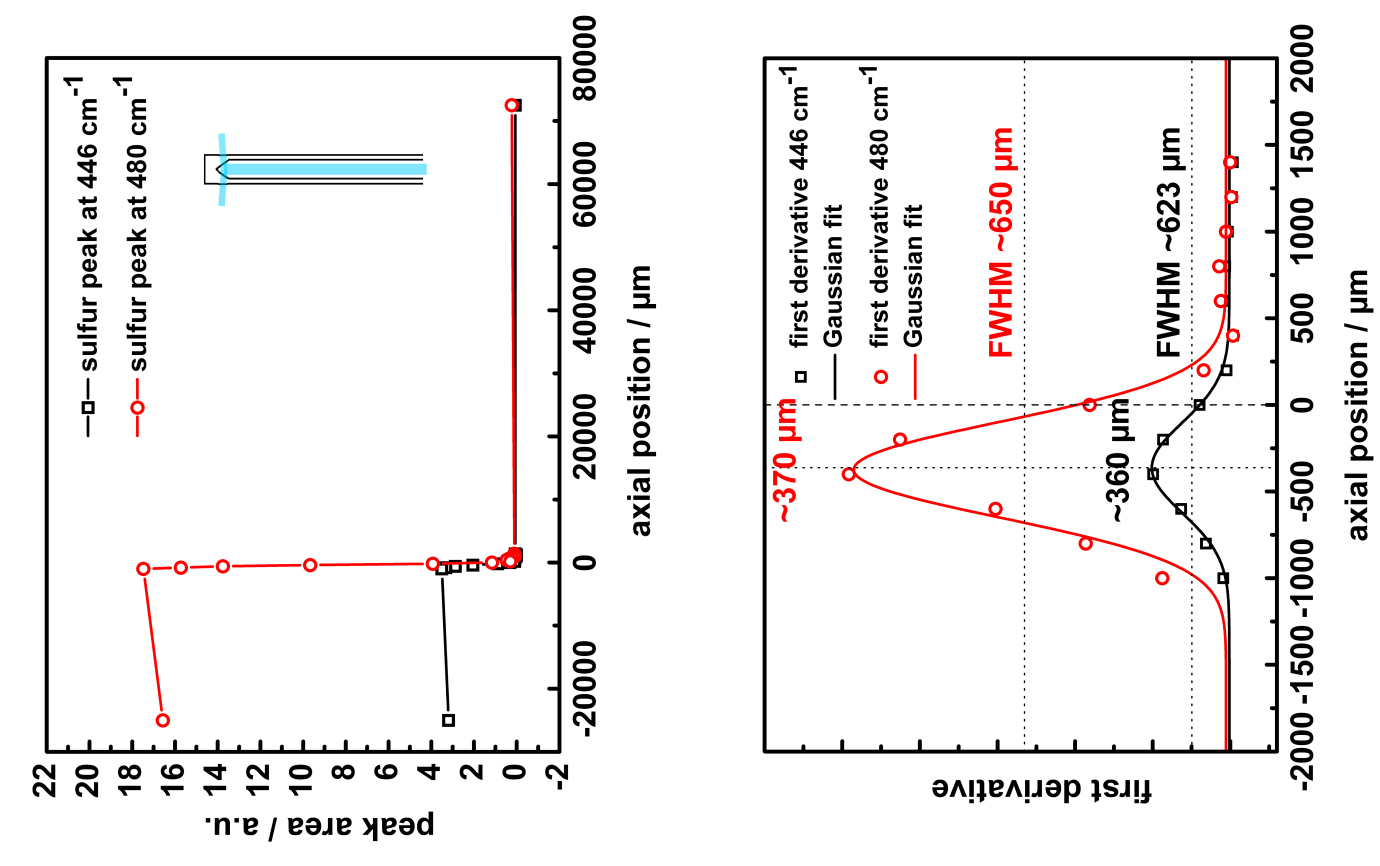

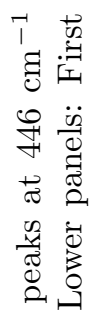

芯

赵

पै

㐘

สี ซี

๑.

茂

ค1

क्षे पै

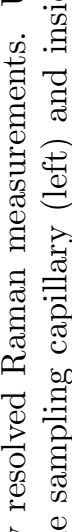

근
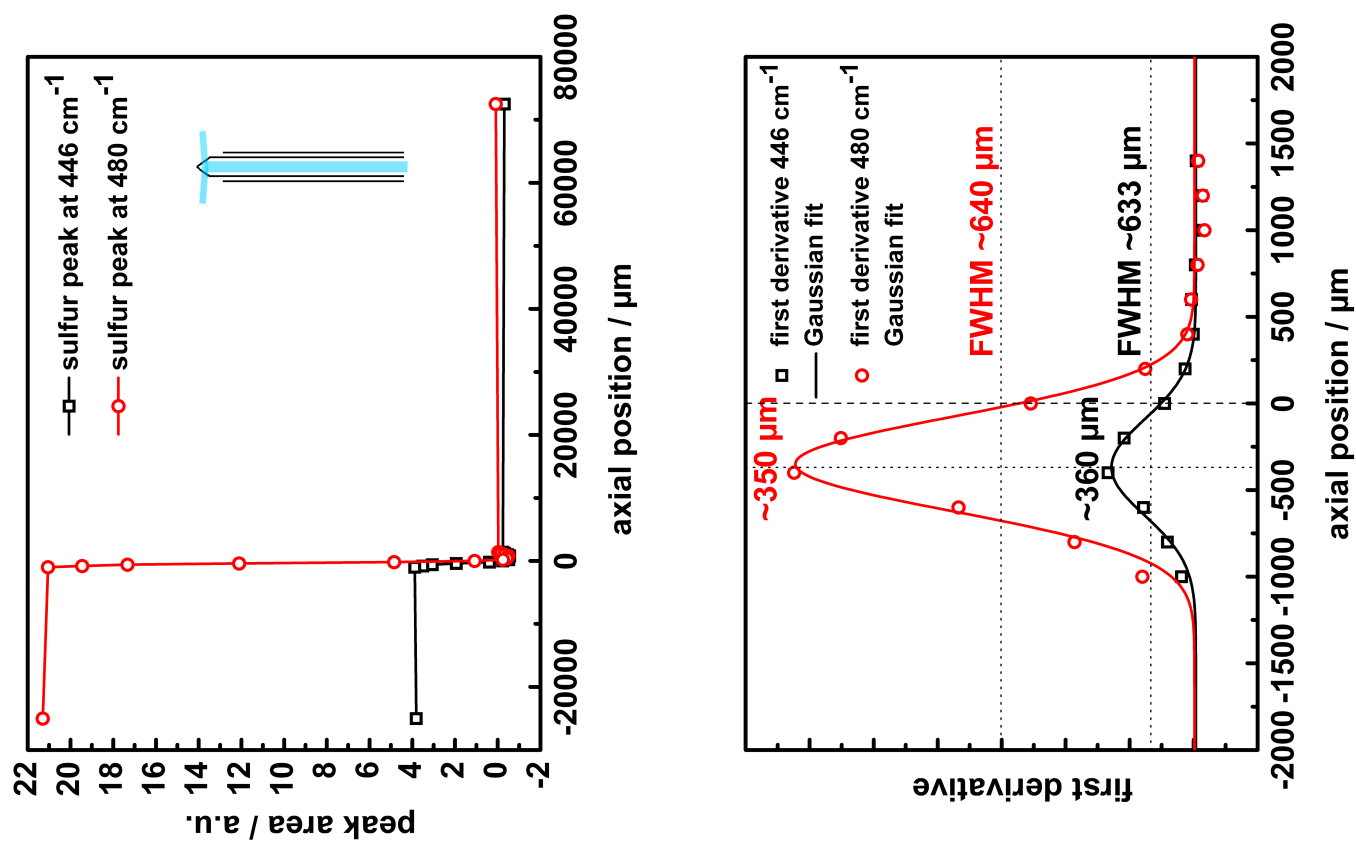

密

औ.

궁

융

$\sum_{-1}^{\infty}$ 드

령

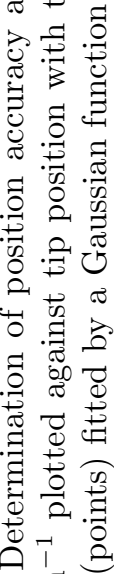

펑

욤

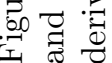




\section{Conclusions}

In this work the principles and applications of spatial profile measurements in a flow reactor have been demonstrated. This rather new method provides detailed measurements of species concentrations, flow rates, phase temperatures and spectroscopic information as a function of position in a chemical reactor with or without a catalyst. After a detailed description of the method and a brief review of its development, application data are presented and analyzed. By means of demonstration experiments on catalytic partial oxidation of methane on $\mathrm{Rh}$ and $\mathrm{Pt}$ foam catalysts, methane oxidative coupling in the gas phase and ethane oxidative dehydrogenation on molybdenum oxide catalysts, it is outlined how spatial reactor profiles can be analyzed to extract mechanistic information about the investigated reaction, e.g. whether parallel or consecutive reactions occur, whether a reaction is influenced by transport processes or not and how the catalyst changes due to the changing chemical potential along the flow coordinate. The use of spatial reactor profiles for validation of microkinetic models is also outlined. Because spatial reactor profiles can be measured at temperature and pressure conditions relevant for industrial reactors, the authors believe that this technique is a valuable extension of the currently available experimental toolbox in chemical reaction engineering research and will find more widespread application in the future.

\section{Acknowledgements}

Our first and foremost thanks go to Prof. Robert Schlögl for hosting the Emmy Noether Junior Research Group 'High Temperature Catalysis' in his Department of Inorganic Chemistry at the Fritz Haber Institute of the Max Planck Society. We are grateful for his continuous support both with scientific input and funds. We would also like to thank Achim Klein-Hoffmann for shaping our pyrometer and Raman fiber probes. The authors thank the German Research Foundation for funding the High Temperature Catalysis Group within the Emmy Noether Program and the German Federal Ministry of Education and Research for providing further funds within the framework of the Excellence Cluster 'Unifying Concepts in Catalysis'. CFG gratefully acknowledges support from the Alexander von Humboldt Foundation.

\section{References}

[1] S. L. Shannon, J. G. Goodwin, Jr., Characterization of Catalytic Surfaces by Isotopic-Transient Kinetics during Steady-State Reaction, Chem. Rev. 95 (3) (1995) 677-695. doi:10.1021/cr00035a011.

[2] J. T. Gleaves, J. R. Ebner, T. C. Kuechler, Catalyst Evaluation System with Submillisecond Time Resolution, Catal. Rev. - Sci. Eng. 30 (1) (1988) 49-116. doi:10.1080/01614948808078616.

[3] J. T. Gleaves, G. Yablonsky, X. Zheng, R. Fushimi, P. L. Mills, Temporal analysis of products (TAP) - Recent advances in technology for kinetic analysis of multi-component catalysts, J. Mol. Catal. A: Chem. 315 (2) (2010) 108-134. doi:10.1016/j.molcata.2009.06.017.

[4] M. Lyubovsky, S. Roychoudhury, R. LaPierre, Catalytic partial "oxidation of methane to syngas" at elevated pressures, Catal. Lett. 99 (3-4) (2005) 113-117. doi:10.1007/s10562-005-2103-y.

[5] W. P. Partridge, J. M. E. Storey, S. A. Lewis, R. W. Smithwick, G. L. Devault, M. J. Cunningham, N. W. Currier, T. M. Yonushonis, Time-Resolved Measurements of Emission Transients By Mass Spectrometry, SAE Int. J. Fuels Lubr. 109 (2000) 2992-2999. doi:10.4271/2000-01-2952.

[6] J. Sá, D. L. Fernandes, F. Aiouache, A. Goguet, C. Hardacre, D. Lundie, W. Naeem, W. P. Partridge, C. Stere, SpaciMS: spatial and temporal operando resolution of reactions within catalytic monoliths, Analyst 135 (9) (2010) 2260-2272. doi:10.1039/C0AN00303D.

[7] M. Bosco, F. Vogel, Optically accessible channel reactor for the kinetic investigation of hydrocarbon reforming reactions, Catal. Today 116 (3) (2006) 348-353. doi:10.1016/j.cattod.2006.05.064.

[8] R. Horn, K. A. Williams, N. J. Degenstein, L. D. Schmidt, Syngas by catalytic partial oxidation of methane on rhodium: Mechanistic conclusions from spatially resolved measurements and numerical simulations, J. Catal. 242 (1) (2006) 92-102. doi:10.1016/j.jcat.2006.05.008

[9] J. Kopyscinski, T. J. Schildhauer, F. Vogel, S. M. A. Biollaz, A. Wokaun, Applying spatially resolved concentration and temperature measurements in a catalytic plate reactor for the kinetic study of $\mathrm{CO}$ methanation, J. Catal. 271 (2) (2010) 262-279. doi:10.1016/j.jcat.2010.02.008. 
[10] C. Daniel, M.-O. Clarté, S.-P. Teh, O. Thinon, H. Provendier, A. C. Van Veen, B. J. Beccard, Y. Schuurman, C. Mirodatos, Spatially resolved catalysis in microstructured reactors by IR spectroscopy: CO oxidation over mono- and bifunctional Pt catalysts, J. Catal. 272 (1) (2010) 55-64. doi:10.1016/j.jcat.2010.03.012.

[11] R. Horn, O. Korup, M. Geske, U. Zavyalova, I. Oprea, R. Schlögl, Reactor for In-Situ Measurements of Spatially Resolved Kinetic Data in Heterogeneous Catalysis, Rev. Sci. Instrum. 81 (6) (2010) 064102. doi:10.1063/1.3428727.

[12] R. Horn, K. A. Williams, N. J. Degenstein, A. Bitsch-Larsen, D. Dalle Nogare, S. A. Tupy, L. D. Schmidt, Methane catalytic partial oxidation on autothermal Rh and Pt foam catalysts: Oxidation and reforming zones, transport effects, and approach to thermodynamic equilibrium, J. Catal. 249 (2) (2007) 380-393. doi:10.1016/j.jcat.2007.05.011

[13] R. Horn, N. J. Degenstein, K. A. Williams, L. D. Schmidt, Spatial and temporal profiles in millisecond partial oxidation processes, Catal. Lett. 110 (3-4) (2006) 169-178. doi:10.1007/s10562-006-0117-8.

[14] A. Bitsch-Larsen, R. Horn, L. D. Schmidt, Catalytic partial oxidation of methane on rhodium and platinum: Spatial profiles at elevated pressure, Appl. Catal., A 348 (2) (2008) 165-172. doi:10.1016/ j.apcata.2008.06.036.

[15] D. Dalle Nogare, N. J. Degenstein, R. Horn, P. Canu, L. D. Schmidt, Modeling spatially resolved profiles of methane partial oxidation on a Rh foam catalyst with detailed chemistry, J. Catal. 258 (1) (2008) 131-142. doi:10.1016/j.jcat.2008.06.006.

[16] D. Dalle Nogare, N. J. Degenstein, R. Horn, P. Canu, L. D. Schmidt, Modeling Spatially Resolved Data of Methane Catalytic Partial Oxidation on Rh Foam Catalyst at Different Inlet Compositions and Flow Rates, J. Catal. 277 (2) (2011) 134-148. doi:10.1016/j.jcat.2010.10.020.

[17] A. Urakawa, A. Baiker, Space-Resolved Profiling Relevant in Heterogeneous Catalysis , Top. Catal. 52 (10) (2009) 1312-1322. doi:10.1007/s11244-009-9312-3

[18] D. A. Hickman, L. D. Schmidt, Production of Syngas by Direct Catalytic Oxidation of Methane, Science 259 (5093) (1993) 343-346. doi:10.1126/science.259.5093.343.

[19] A. Donazzi, M. Maestri, B. C. Michel, A. Beretta, P. Forzatti, G. Groppi, E. Tronconi, L. D. Schmidt, D. G. Vlachos, Microkinetic Modeling of Spatially Resolved Autothermal $\mathrm{CH}_{4}$ Catalytic Partial Oxidation Experiments over Rh-coated Foams., J. Catal. 275 (2010) 270-279. doi:10.1016/j.jcat.2010. 08.007 .

[20] L. L. Raja, R. J. Kee, O. Deutschmann, J. Warnatz, L. D. Schmidt, A critical evaluation of NavierStokes, boundary-layer, and plug-flow models of the flow and chemistry in a catalytic-combustion monolith, Catal. Today 59 (1-2) (2000) 47-60. doi:10.1016/S0920-5861(00)00271-6.

[21] G. Incera Garridoa, F. Patcas, S. Langa, B. Kraushaar-Czarnetzki, Mass transfer and pressure drop in ceramic foams: A description for different pore sizes and porosities, Chem. Eng. Sci. 63 (21) (2008) 5202-5217. doi:10.1016/j.ces.2008.06.015.

[22] G. Groppi, L. Giani, E. Tronconi, Generalized Correlation for Gas/Solid Mass-Transfer Coefficients in Metallic and Ceramic Foams, Ind. Eng. Chem. Res. 46 (12) (2007) 3955-3958. doi:10.1021/ie061330g.

[23] B. Dietrich, W. Schabel, M. Kind, H. Martin, Pressure drop measurements of ceramic spongesDetermining the hydraulic diameter, Chem. Eng. Sci. 64 (16) (2009) 3633-3640. doi:10.1016/j. ces.2009.05.005.

[24] M. V. Twigg, J. T. Richardson, Theory and Applications of Ceramic Foam Catalysts, Trans. IChemE 80 (2) (2002) 183-189. doi:10.1205/026387602753501906.

[25] M.-L. Wang, H.-Z. Zheng, J.-M. Li, W.-Z. Weng, W.-S. Xia, C.-J. Huang, H.-L. Wan, In Situ Raman and Pulse Reaction Study on the Partial Oxidation of Methane to Synthesis Gas over a $\mathrm{Pt} / \mathrm{Al}_{2} \mathrm{O}_{3}$ Catalyst, Chemistry - An Asian Journal 6 (2) (2011) 580-589. doi:10.1002/asia.201000580.

[26] A. B. Mhadeshwar, D. G. Vlachos, A Catalytic Reaction Mechanism for Methane Partial Oxidation at Short Contact Times, Reforming, and Combustion, and for Oxygenate Decomposition and Oxidation on Platinum., Ind. Eng. Chem. Res. 46 (16) (2007) 5310-5324. doi:10.1021/ie070322c. 
[27] R. Quiceno, J. Pérez-Ramírez, J. Warnatz, O. Deutschmann, Modeling the high-temperature catalytic partial oxidation of methane over platinum gauze: Detailed gas-phase and surface chemistries coupled with 3D flow field simulations, Appl. Catal., A 303 (2006) 166-176. doi:10.1016/j.apcata.2006.01. 041 .

[28] E. V. Kondratenko, M. Baerns, Handbook of Heterogeneous Catalysis, 2nd Edition, Vol. 6, Wiley-VCH Verlag GmbH \& Co. KGaA, Weinheim, 2008, Ch. 13.17 Oxidative Coupling of Methane, pp. 3010-3023. doi:10.1002/9783527610044.hetcat0152.

[29] G. E. Keller, M. M. Bhasin, Synthesis of ethylene via oxidative coupling of methane: I. Determination of active catalysts, J. Catal. 73 (1) (1982) 9-19. doi:10.1016/0021-9517(82)90075-6.

[30] A. M. Maitra, Critical performance evaluation of catalysts and mechanistic implications for oxidative coupling of methane, Appl. Catal., A 104 (1) (1993) 11-59. doi:10.1016/0926-860X (93) 80209-9.

[31] C. L. Rasmussen, J. G. Jakobsen, P. Glarborg, Experimental measurements and kinetic modeling of $\mathrm{CH}_{4} / \mathrm{O}_{2}$ and $\mathrm{CH}_{4} / \mathrm{C}_{2} \mathrm{H}_{6} / \mathrm{O}_{2}$ conversion at high pressure, Int. J. Chem. Kinet. 40 (12) (2008) 778-807. doi:10.1002/kin.20352,

[32] Chemkin-pro 15101 (2010).

[33] H. Zanthoff, M. Baerns, Oxidative coupling of methane in the gas phase. Kinetic simulation and experimental verification, Ind. Eng. Chem. Res. 29 (1) (1990) 2-10. doi:10.1021/ie00097a001.

[34] T. Blasco, J. M. López Nieto, Oxidative dyhydrogenation of short chain alkanes on supported vanadium oxide catalysts, Appl. Catal., A 157 (1-2) (1997) 117-142. doi:10.1016/S0926-860X(97)00029-X.

[35] F. Cavani, N. Ballarini, A. Cericola, Oxidative dehydrogenation of ethane and propane: How far from commercial implementation?, Catal. Today 127 (1-4) (2007) 113-131. doi:10.1016/j.cattod.2007. 05.009 